\title{
Introducing Atomic Separation Axioms on Atomic Measure Space - An Advanced Study
}

\author{
S. C. P. Halakatti ${ }^{1}$, Akshata Kengangutti $^{2}$ \\ ${ }^{I}$ Department of Mathematics Karnatak University, Dharwad, Karnataka, INDIA. \\ ${ }^{2}$ Research Scholar, Department of Mathematics, Karnatak University, Dharwad, Karnataka, INDIA.
}

\begin{abstract}
A$ study on atomic separation axioms on atomic measure space $\left(R^{n}, \tau, \Sigma, \mu_{A}\right)$ has been introduced in this paper. The key feature of this study is that, the atomic separation axioms like $A T_{2}$, AR are not only invariant under homeomorphism but they are invariant under measure invariant transformation on an atomic measure $\operatorname{space}\left(R^{n}, \tau, \Sigma, \mu_{A}\right)$.
\end{abstract}

Keywords:, Atomic measure space, Atomic separation axioms, Measure atlas, Measure chart, Measure invariant transformation, Measure manifold, Measure space.

\section{Introduction}

It is observed that, the topological structure on $\left(\mathrm{R}^{\mathrm{n}}, \tau\right)$ generates an algebraic structure $\sigma$ algebra $\Sigma$, that transforms the topological space [3],[6] into a measurable space $\left(\mathrm{R}^{\mathrm{n}}, \tau, \Sigma\right)$ [2],[4]. By admitting a suitable measure function $\mu$, the measurable space is designated as a measure space $\left(\mathrm{R}^{\mathrm{n}}, \tau, \Sigma\right.$, $\mu$ ). As a particular case, by introducing an atomic measure $\mu_{\mathrm{A}}$ [5], a measure space is re-designated as atomic measure space $\left(\mathrm{R}^{\mathrm{n}}, \tau, \Sigma, \mu_{\mathrm{A}}\right)$. In this paper S. C. P. Halakatti has introduced a study on extended version of separation axioms of a topological space $\left(\mathrm{R}^{\mathrm{n}}, \tau\right)$ onto an atomic measure space $\left(\mathrm{R}^{\mathrm{n}}, \tau, \Sigma, \mu_{\mathrm{A}}\right)$ and re-defined them as atomic separation axioms on $\left(\mathrm{R}^{\mathrm{n}}, \tau, \Sigma, \mu_{\mathrm{A}}\right)$. The significance of such extension of separation axioms on $\left(\mathrm{R}^{\mathrm{n}}, \tau, \Sigma, \mu_{\mathrm{A}}\right)$ is that these topological properties are not only invariant under homeomorphism but they are invariant under measure invariant transformation. This has an important implication in the study of measure manifold [1], the concept has been first introduced by S. C. P. Halakatti. The study of atomic separation axioms on the measure manifold has its applications in the field of cosmology, where the universe could be modeled as atomic measure manifold. The atomic separation axioms explicitly explain the expansion of the universe as the intrinsic property of atomic measure manifold. Our next work will deal with some inherent properties of atomic measure manifold.

\subsection{Definition: Topological Space}

\section{Some Preliminaries}

A set $R^{n}$ with a collection $\tau$ of subset of $R^{n}$ is said to be a topology on $R^{n}$ if the following axioms are satisfied:

i) $\quad \mathrm{R}^{\mathrm{n}}, \emptyset \in \tau$

ii) Arbitrary union of members of $\tau$ is again a member of $\tau$

i.e., $\forall\left\{\mathrm{G}_{\lambda}: \lambda \in \Lambda\right\} \in \tau$ we have $U_{\lambda \in \Lambda} \mathrm{G}_{\lambda} \in \tau$

iii) Intersection of finitely many members of $\tau$ is again a member of $\tau$

i.e., $\forall\left\{\mathrm{G}_{\mathrm{i}}: \mathrm{i}=1,2, \ldots . \mathrm{n}\right\} \in \tau$ we have $\bigcap_{\mathrm{i}=1}^{\mathrm{n}} \mathrm{G}_{\mathrm{i}} \in \tau$

The ordered pair $\left(R^{n}, \tau\right)$ is called a topological space.

\subsection{Definition: $\sigma$ - algebra}

A $\sigma-$ algebra on a topological space $\left(\mathrm{R}^{\mathrm{n}}, \tau\right)$ is a collection $\Sigma$ of subsets of $\mathrm{R}^{\mathrm{n}}$ such that

i) $\quad \mathrm{R}^{\mathrm{n}}, \emptyset \in \Sigma$

ii) If $\mathrm{A} \in \Sigma$ then $\mathrm{A}^{\mathrm{c}} \in \Sigma$

iii) If $A_{i} \in \Sigma$ for $i \in N$ then

$\bigcup_{\mathrm{i}=1}^{\infty} A_{\mathrm{i}} \in \Sigma, \bigcap_{\mathrm{i}=1}^{\infty} A_{\mathrm{i}} \in \Sigma$

The triplet $\left(\mathrm{R}^{\mathrm{n}}, \tau, \Sigma\right)$ is called a measure space.

2.3 Definition: $\mathrm{G}_{\delta}$ - set

A subset $\mathrm{A} \subseteq \mathrm{R}^{\mathrm{n}}$ is called a $\mathrm{G}_{\delta}$ - set if it is the countable intersection of open sets

i.e., $A=\left\{\bigcap_{i=1}^{\infty} A_{i}: A_{i} \in \tau\right\}$ 
2.4 Definition: $F_{\sigma}-$ set

A subset $\mathrm{E} \subseteq \mathrm{R}^{\mathrm{n}}$ is called a $\mathrm{F}_{\sigma}$ - set provided it is the countable union of closed set i.e., $E=\left\{U_{i=1}^{\infty} E_{i}: E_{i} \in \tau^{c}\right\}$

\subsection{Definition: Borel $\sigma-$ algebra}

The Borel $\sigma$ - algebra $B\left(R^{n}\right)$ on $\left(R^{n}, \tau\right)$ is the smallest $\sigma$ - algebra generated by the open sets belonging to $\tau$ such that

$$
\mathrm{B}\left(\mathrm{R}^{\mathrm{n}}\right)=\Sigma\left(\tau\left(\mathrm{R}^{\mathrm{n}}\right)\right)
$$

A set that belongs to the $\sigma-$ algebra is called Borel set.

\section{Remark:}

Every $\mathrm{G}_{\delta}$ - set is a Borel open set, since $\left(\mathrm{R}^{\mathrm{n}}, \tau, \Sigma\right)$ is measurable space the complement of $\mathrm{G}_{\delta}$ - set is $\mathrm{F}_{\sigma}$ - set, every $\mathrm{F}_{\sigma}$ - set is a Borel closed set.

\subsection{Definition: Measurable Function}

Let $\left(\mathrm{R}^{\mathrm{n}}, \tau_{1}, \Sigma_{1}\right)$ and $\left(\mathrm{R}^{\mathrm{m}}, \tau_{2}, \Sigma_{2}\right)$ be measurable spaces. A function $\mathrm{T}: \mathrm{R}^{\mathrm{n}} \rightarrow \mathrm{R}^{\mathrm{m}}$ is said to be measurable function if the inverse image of every measurable set is measurable

i.e., $\mathrm{T}^{-1}(\mathrm{~A}) \in\left(\mathrm{R}^{\mathrm{n}}, \tau_{1}, \Sigma_{1}\right)$

for every measurable subset $\mathrm{A} \subseteq\left(\mathrm{R}^{\mathrm{m}}, \tau_{2}, \Sigma_{2}\right)$.

Now let us introduce the concept of measure on measurable space $\left(\mathrm{R}^{\mathrm{n}}, \tau, \Sigma\right)$. A measure is a countably additive, non-negative extended real-valued function on a $\sigma$-algebra of $\left(\mathrm{R}^{\mathrm{n}}, \tau, \Sigma\right)$.

\subsection{Definition: Measure Space $\left(\mathrm{R}^{\mathrm{n}}, \tau, \Sigma, \mu\right)$}

A measure $\mu$ on a measurable space $\left(\mathrm{R}^{\mathrm{n}}, \tau, \Sigma\right)$ is a function

such that

$$
\mu: \Sigma \rightarrow[0, \infty]
$$

a) $\quad \mu(\varnothing)=0$

b) If $\left\{A_{i} \in \Sigma\right.$ for $\left.i \in N\right\}$ is a countable disjoint collection of sets in $\Sigma$, then

$\mu\left(\cup_{i=1}^{\infty} A_{i}\right)=\sum_{i=1}^{\infty} \mu\left(A_{i}\right) \ldots \ldots \ldots$ (Countable additivity).

Therefore the space $\left(\mathrm{R}^{\mathrm{n}}, \tau, \Sigma, \mu\right)$ is called a measure space.

\subsection{Definition: Restriction of Measure}

If $\left(\mathrm{R}^{\mathrm{n}}, \tau, \Sigma, \mu\right)$ is a measure space and $\mathrm{E} \subseteq \mathrm{R}^{\mathrm{n}}$ is a measurable subset, then the measure subspace $\left(\mathrm{E}, \tau / \mathrm{E}, \Sigma_{/ \mathrm{E}}, \mu / \mathrm{E}\right)$ is defined by restricting $\mu$ to $\mathrm{E}$ :

$$
\Sigma_{/ \mathrm{E}}=\{\mathrm{A} \cap \mathrm{E}: \mathrm{A} \in \Sigma\}, \mu / \mathrm{E}(\mathrm{A} \cap \mathrm{E})=\mu(\mathrm{A} \cap \mathrm{E})
$$

\subsection{Definition: Sets of Measure Zero}

A set of measure zero or a null set is a measurable set $\mathrm{N}$ such that $\mu(\mathrm{N})=0$.

A property which holds for all $\mathrm{x} \in \mathrm{R}^{\mathrm{n}} \backslash \mathrm{N}$ where $\mathrm{N}$ is a set of measure zero is said to hold almost everywhere ( or $\mu$ - a.e).

In general, a subset of a measure zero need not be measurable but if it is, it must have measure zero.

\subsection{Definition: Complete Measure Space}

A measure space $\left(\mathrm{R}^{\mathrm{n}}, \tau, \Sigma, \mu\right)$ is complete if every subset of a set $\mathrm{N}$ of measure zero is measurable. i.e., $\mathrm{A} \subseteq \mathrm{N}: \mu(\mathrm{N})=0$, then $\mathrm{A}$ is measurable and $\mu(\mathrm{A})=0$.

\subsection{Definition: Measure Preserving Transformation/Invariant Measure}

Let $\left(\mathrm{R}^{\mathrm{n}}, \tau_{1}, \Sigma_{1}, \mu_{1}\right)$ and $\left(\mathrm{R}^{\mathrm{m}}, \tau_{2}, \Sigma_{2}, \mu_{2}\right)$ be measure spaces and $\mathrm{T}:\left(\mathrm{R}^{\mathrm{n}}, \tau_{1}, \Sigma_{1}, \mu_{1}\right) \rightarrow\left(\mathrm{R}^{\mathrm{m}}, \tau_{2}, \Sigma_{2}, \mu_{2}\right)$ be a measurable transformation. The transformation $\mathrm{T}$ is said to be measure preserving if for all $\mathrm{A} \in \Sigma_{2}$ we have that

\section{Note:}

$$
\mu_{1}\left(\mathrm{~T}^{-1}(\mathrm{~A})\right)=\mu_{2}(\mathrm{~A})
$$

1) In this paper the smallest open sets $G_{\delta}$ and closed sets $F_{\sigma}$ are Borel sets belonging to the $\sigma$-algebra $\Sigma$ and the Borel open sets are denoted by the letters A, B and Borel closed sets by E, F.

2) Now onwards we denote $\mu$ for general measure space $\left(\mathrm{R}^{\mathrm{n}}, \tau, \Sigma, \mu\right)$ and $\mu_{\mathrm{A}}$ for Atomic measure space $\left(\mathrm{R}^{\mathrm{n}}, \tau, \Sigma, \mu_{\mathrm{A}}\right)$. Now we shall introduce the concept of atomic measure on measure space $\left(\mathrm{R}^{\mathrm{n}}, \tau, \Sigma, \mu_{\mathrm{A}}\right)$. 


\subsection{Definition: Atom}

Given a measurable space $\left(\mathrm{R}^{\mathrm{n}}, \tau, \Sigma\right)$ and a measure $\mu_{\mathrm{A}}$ on that space, a set $\mathrm{A}$ in $\Sigma$ is called an atom if $\mu_{\mathrm{A}}(\mathrm{A})>0$ and for any measurable subset $\mathrm{B}$ of $\mathrm{A}$ has either $\mu_{\mathrm{A}}(\mathrm{B})=0$ or $\mu_{\mathrm{A}}(\mathrm{B})=\mu_{\mathrm{A}}(\mathrm{A})$.

\subsection{Definition: Atomic Measure Space $\left(\mathrm{R}^{\mathrm{n}}, \tau, \Sigma, \boldsymbol{\mu}_{\mathrm{A}}\right)$}

Let $\left(\mathrm{R}^{\mathrm{n}}, \tau, \Sigma, \mu_{\mathrm{A}}\right)$ be a measure space. A measure $\mu_{\mathrm{A}}$ is called atomic if every set $\mathrm{A} \in \Sigma$ such that $\mu_{\mathrm{A}}(\mathrm{A})>0$ contains an atom i.e. for any measurable subset $\mathrm{B}$ of $\mathrm{A}$ has either $\mu_{\mathrm{A}}(\mathrm{B})=0$ or $\mu_{\mathrm{A}}(\mathrm{B})$ $=\mu_{\mathrm{A}}(\mathrm{A})$. The measure space $\left(\mathrm{R}^{\mathrm{n}}, \tau, \Sigma, \mu_{\mathrm{A}}\right)$ with atomic measure $\mu_{\mathrm{A}}$ is called an atomic measure space.

In [1] S. C. P. Halakatti has introduced the concepts of measurable chart, measure chart, measurable atlas, measure atlas, measurable and measure manifolds.

\subsection{Definition: Chart}

For every $\mathrm{V} \in\left(\mathrm{R}^{\mathrm{n}}, \tau, \Sigma\right)$ there exists a homeomorphism $\varphi$ and $\varphi^{-1}$ and defined $\varphi: \varphi^{-1}(\mathrm{~V}) \rightarrow\left(\mathrm{R}^{\mathrm{n}}, \tau, \Sigma\right)$ such that $\varphi\left(\varphi^{-1}(\mathrm{~V})=\mathrm{U}\right)=\mathrm{V} \subset\left(\mathrm{R}^{\mathrm{n}}, \tau, \Sigma\right)$, then the pair $(\mathrm{U}, \varphi)$ is called the chart.

\subsection{Definition: Measurable chart}

Let $\left(\mathrm{U}, \tau_{1 / \mathrm{U}}, \Sigma_{1 / \mathrm{U}}\right) \subseteq\left(\mathrm{M}, \tau_{1}, \Sigma_{1}\right)$ be a non-empty measurable subspace of $\left(\mathrm{M}, \tau_{1}, \Sigma_{1}\right)$

if there exists a map $\varphi:\left(\mathrm{U}, \tau_{1 / \mathrm{U}}, \Sigma_{1 / \mathrm{U}}\right) \rightarrow \varphi\left(\mathrm{U}, \tau_{1 / \mathrm{U}}, \Sigma_{1 / \mathrm{U}}\right) \subseteq\left(\mathrm{R}^{\mathrm{n}}, \tau, \Sigma\right)$

satisfying following conditions:

(i) $\varphi$ is homeomorphism

(ii) $\varphi$ is measurable if for every measurable subset $\mathrm{V} \in\left(\mathrm{R}^{\mathrm{n}}, \tau, \Sigma\right)$,

$\varphi^{-1}(\mathrm{~V}) \in\left(\mathrm{M}, \tau_{1}, \Sigma_{1}\right)$ is also measurable.

Then the structure $\left(\left(\mathrm{U}, \tau_{1 / \mathrm{U}}, \Sigma_{1 / \mathrm{U}}\right), \varphi\right)$ is called a measurable chart.

\subsection{Definition: Measurable Atlas}

By an $R^{n}$ measurable atlas of class $C^{k}$ on $M$ we mean a countable collection $\left(A, \tau_{1 / A}, \Sigma_{1 / A}\right)$ of $n$ dimensional measurable charts $\left(\left(\mathrm{U}_{\mathrm{n}}, \tau_{1} / \mathrm{U}_{\mathrm{n}}, \Sigma_{1} / \mathrm{U}_{\mathrm{n}}\right), \varphi_{\mathrm{n}}\right)$ for all $\mathrm{n} \in \mathrm{N}$ on $\left(\mathrm{M}, \tau_{1}, \Sigma_{1}\right)$ subject to the following conditions:

$\left(\mathrm{a}_{1}\right) \cup_{\mathrm{n}=1}^{\infty}\left(\left(\mathrm{U}_{\mathrm{n}}, \tau_{1} / \mathrm{U}_{\mathrm{n}}, \Sigma_{1} / \mathrm{U}_{\mathrm{n}}\right), \varphi_{\mathrm{n}}\right)=\mathrm{M}$

i.e., the countable union of the measurable charts in $\left(\mathrm{A}, \tau_{1 / \mathrm{A}}, \Sigma_{1 / \mathrm{A}}\right)$ cover $\left(\mathrm{M}, \tau_{1}, \Sigma_{1}\right)$

$\left(\mathrm{a}_{2}\right)$ for any pair of measurable charts $\left(\left(\mathrm{U}_{\mathrm{n}}, \tau_{1} / \mathrm{U}_{\mathrm{n}}, \Sigma_{1} / \mathrm{U}_{\mathrm{n}}\right), \varphi_{\mathrm{n}}\right)$ and

$\left(\left(U_{m}, \tau_{1} / U_{m}, \Sigma_{1} / U_{m}\right), \varphi_{m}\right)$ in $\left(A, \tau_{1 / A}, \Sigma_{1 / A}\right)$ the transition maps $\varphi_{n} \circ \varphi_{m}{ }^{-1}$ and $\varphi_{m} \circ \varphi_{n}{ }^{-1}$ are

(1) differentiable maps of class $C^{k}(k \geq 1)$ i.e.,

$\varphi_{\mathrm{n}} \circ \varphi_{\mathrm{m}}^{-1}: \varphi_{\mathrm{m}}\left(\mathrm{U}_{\mathrm{n}} \cap \mathrm{U}_{\mathrm{m}}\right) \rightarrow \varphi_{\mathrm{n}}\left(\mathrm{U}_{\mathrm{n}} \cap \mathrm{U}_{\mathrm{m}}\right) \subseteq\left(\mathrm{R}^{\mathrm{n}}, \tau, \Sigma\right)$

$\varphi_{\mathrm{m}} \circ \varphi_{\mathrm{n}}^{-1}: \varphi_{\mathrm{n}}\left(\mathrm{U}_{\mathrm{n}} \cap \mathrm{U}_{\mathrm{m}}\right) \rightarrow \varphi_{\mathrm{m}}\left(\mathrm{U}_{\mathrm{n}} \cap \mathrm{U}_{\mathrm{m}}\right) \subseteq\left(\mathrm{R}^{\mathrm{n}}, \tau, \Sigma\right)$

are differential maps of class $\mathrm{C}^{\mathrm{k}}(\mathrm{k} \geq 1)$

(2) Measurable i.e., these two transition maps $\varphi_{\mathrm{n}} \circ \varphi_{\mathrm{m}}^{-1}$ and $\varphi_{\mathrm{m}} \circ \varphi_{\mathrm{n}}^{-1}$ are measurable functions if,

(a) For any measurable subset $\mathrm{K} \subseteq \varphi_{\mathrm{m}}\left(\mathrm{U}_{\mathrm{n}} \cap \mathrm{U}_{\mathrm{m}}\right)$,

$\left(\varphi_{\mathrm{n}} \circ \varphi_{\mathrm{m}}{ }^{-1}\right)^{-1}(\mathrm{~K}) \in \varphi_{\mathrm{m}}\left(\mathrm{U}_{\mathrm{n}} \cap \mathrm{U}_{\mathrm{m}}\right)$ is also measurable.

(b) for any measurable subset $\mathrm{S} \subseteq \varphi_{\mathrm{m}}\left(\mathrm{U}_{\mathrm{n}} \cap \mathrm{U}_{\mathrm{m}}\right)$,

$\left(\varphi_{\mathrm{m}} \circ \varphi_{\mathrm{n}}^{-1}\right)^{-1}(\mathrm{~S}) \in \varphi_{\mathrm{n}}\left(\mathrm{U}_{\mathrm{n}} \cap \mathrm{U}_{\mathrm{m}}\right)$ is also measurable.

\subsection{Definition: Measure chart}

A measurable chart $\left(\left(U, \tau_{1 / \mathrm{U}}, \Sigma_{1 / \mathrm{U}}\right), \varphi\right)$ equipped with a measure $\mu_{1} / \mathrm{U}$ is called a measure chart, denoted by $\left(\left(\mathrm{U}, \tau_{1 / \mathrm{U}}, \Sigma_{1 / \mathrm{U}}, \mu_{1 / \mathrm{U}}\right), \varphi\right)$ satisfying following conditions:

(i) $\varphi$ is homeomorphism

(ii) $\varphi$ is measurable if for every measurable subset $\mathrm{V} \in\left(\mathrm{R}^{\mathrm{n}}, \tau, \Sigma\right)$,

$\varphi^{-1}(\mathrm{~V}) \in\left(\mathrm{M}, \tau_{1}, \Sigma_{1}\right)$ is also measurable.

(iii) $\varphi$ is measure preserving map.

Then the structure $\left(\left(\mathrm{U}, \tau_{1 / \mathrm{U}}, \Sigma_{1 / \mathrm{U}}, \mu_{1 / \mathrm{U}}\right), \varphi\right)$ is called a measure chart. 


\subsection{Definition: Measure Atlas}

By an $R^{n}$ measure atlas of class $C^{k}$ on $M$ we mean a countable collection $\left(A, \tau_{1 / A}, \Sigma_{1 / /} A, \mu 1_{/ A}\right)$ of ndimensional measure charts $\left(\left(U_{n}, \tau_{1 / U_{n}}, \Sigma_{1 / U_{n}}, \mu_{1 / U_{n}}\right), \varphi_{n}\right)$ for all $n \in N$ on $\left(M, \tau_{1}, \Sigma_{1}, \mu_{1}\right)$ satisfying the following conditions:

$\left(a_{1}\right) \bigcup_{n=1}^{\infty}\left(\left(U_{n}, \tau_{1 / U_{n}}, \Sigma_{1 / U_{n}}, \mu_{1 / U_{n}}\right), \varphi_{n}\right)=M$

i.e., the countable union of the measure charts in $\left(\mathrm{A}, \tau_{1 / \mathrm{A}}, \Sigma_{1 / \mathrm{A}} \mathrm{A}, \mu_{1 / \mathrm{A}}\right)$ cover $\left(\mathrm{M}, \tau_{1}, \Sigma_{1}, \mu_{1}\right)$

$\left(\mathrm{a}_{2}\right)$ for any pair of measure charts $\left(\left(\mathrm{U}_{\mathrm{n}}, \tau_{1 / \mathrm{U}_{\mathrm{n}}}, \Sigma_{1 / \mathrm{U}_{\mathrm{n}}}, \mu_{1 / \mathrm{U}_{\mathrm{n}}}\right) \varphi_{\mathrm{n}}\right)$ and

$\left(\left(\mathrm{U}_{\mathrm{m}}, \tau_{1 / \mathrm{U}_{\mathrm{m}}}, \Sigma_{1 / \mathrm{U}_{\mathrm{m}}}, \mu_{1 / \mathrm{U}_{\mathrm{m}}}\right), \varphi_{\mathrm{m}}\right)$ in $\left(\mathrm{A}, \tau_{1 / \mathrm{A}}, \Sigma_{1 / A} \mathrm{~A}, \mu 1_{/ \mathrm{A}}\right)$, the transition maps $\varphi_{\mathrm{n}} \circ \varphi_{\mathrm{m}}{ }^{-1}$ and $\varphi_{\mathrm{m}} \circ \varphi_{\mathrm{n}}{ }^{-1}$ are

(1) differentiable maps of class $C^{\mathrm{k}}(\mathrm{k} \geq 1)$ i.e.,

$\varphi_{\mathrm{n}} \circ \varphi_{\mathrm{m}}^{-1}: \varphi_{\mathrm{m}}\left(\mathrm{U}_{\mathrm{n}} \cap \mathrm{U}_{\mathrm{m}}\right) \rightarrow \varphi_{\mathrm{n}}\left(\mathrm{U}_{\mathrm{n}} \cap \mathrm{U}_{\mathrm{m}}\right) \subseteq\left(\mathrm{R}^{\mathrm{n}}, \tau, \Sigma, \mu\right)$

$\varphi_{\mathrm{m}} \circ \varphi_{\mathrm{n}}^{-1}: \varphi_{\mathrm{n}}\left(\mathrm{U}_{\mathrm{n}} \cap \mathrm{U}_{\mathrm{m}}\right) \rightarrow \varphi_{\mathrm{m}}\left(\mathrm{U}_{\mathrm{n}} \cap \mathrm{U}_{\mathrm{m}}\right) \subseteq\left(\mathrm{R}^{\mathrm{n}}, \tau, \Sigma, \mu\right)$

are differential maps of class $\mathrm{C}^{\mathrm{k}}(\mathrm{k} \geq 1)$

(2) Measurable i.e., these two transition maps $\varphi_{\mathrm{n}} \circ \varphi_{\mathrm{m}}{ }^{-1}$ and $\varphi_{\mathrm{m}} \circ \varphi_{\mathrm{n}}{ }^{-1}$ are measurable functions if,

(c) For any measurable subset $K \subseteq \varphi_{\mathrm{n}}\left(\mathrm{U}_{\mathrm{n}} \cap \mathrm{U}_{\mathrm{m}}\right)$,

$\left(\varphi_{\mathrm{n}} \circ \varphi_{\mathrm{m}}{ }^{-1}\right)^{-1}(\mathrm{~K}) \in \varphi_{\mathrm{m}}\left(\mathrm{U}_{\mathrm{n}} \cap \mathrm{U}_{\mathrm{m}}\right)$ is also measurable.

(d) for any measurable subset $\mathrm{S} \subseteq \varphi_{\mathrm{m}}\left(\mathrm{U}_{\mathrm{n}} \cap \mathrm{U}_{\mathrm{m}}\right)$,

$\left(\varphi_{\mathrm{m}} \circ \varphi_{\mathrm{n}}^{-1}\right)^{-1}(\mathrm{~S}) \in \varphi_{\mathrm{n}}\left(\mathrm{U}_{\mathrm{n}} \cap \mathrm{U}_{\mathrm{m}}\right)$ is also measurable.

$\left(a_{3}\right)$ for any two measure atlases $\left(A_{1}, \tau_{1 / A_{1}}, \Sigma_{1 / A_{1}}, \mu_{1 / A_{1}}\right)$ and $\left(A_{2}, \tau_{1 / A_{2}}, \Sigma_{1 / A_{2}}, \mu_{1 / A_{2}}\right)$ we say that a mapping, $\mathrm{T}: \mathrm{A}_{1} \rightarrow \mathrm{A}_{2}$ is measurable if $\mathrm{T}^{-1}(E)$ is measurable for every measurable chart

$\mathrm{E}=\left(\left(\mathrm{U}, \tau_{1 / \mathrm{U}}, \Sigma_{1 / \mathrm{U}}, \mu_{1 / \mathrm{U})}, \varphi\right) \subset\left(\mathrm{A}_{2}, \tau_{1 / \mathrm{A}_{2}}, \Sigma_{1 / \mathrm{A}_{2}}, \mu_{1 / \mathrm{A}_{2}}\right)\right.$, and the mapping is measure preserving if

$\mu_{1 / A_{1}}\left(T^{-1}(E)\right)=\mu_{1 / A_{2}}(E)$, where $A_{1} \sim A_{2}$ and $\mu_{1 / A_{1}}=\mu_{1 / A_{2}}$.

Then we call $\mathrm{T}$ a transformation.

$\left(\mathrm{a}_{4}\right)$ If a measurable transformation $\mathrm{T}: \mathrm{A} \rightarrow \mathrm{A}$ preserves a measure $\mu_{1}$ then we say that $\mu_{1}$ is $\mathrm{T}$-invariant (or invariant under $\mathrm{T}$ ). If $\mathrm{T}$ is invariant and if both $\mathrm{T}$ and $\mathrm{T}^{-1}$ are measurable and measure preserving then we call $\mathrm{T}$ an invertible measure preserving transformation.

A non-empty set $\mathrm{M}$ equipped with differentiable structure, topological structure and algebraic structure $\sigma$-algebra is called Measurable Manifold. A measure $\mu_{1}$ defined on (M, $\left.\tau_{1}, \Sigma_{1}\right)$ and the quadruple (M, $\tau_{1}, \Sigma_{1}, \mu_{1}$ ) is called Measure Manifold.

\section{Introducing Atomic Separation Axioms On Atomic Measure Space}

In this paper it is observed that the topological structure on $\mathrm{R}^{\mathrm{n}}$ carries topological properties in terms of open /closed sets belonging to $\left(\mathrm{R}^{\mathrm{n}}, \tau, \Sigma\right)$. On such topological space when an algebraic structure $\sigma-$ algebra $\Sigma$ is introduced, the topological space $\tau$ transforms into a measurable space which admits a measure $\mu$. We are here introducing an atomic measure $\Omega_{A}$ on $\left(\mathrm{R}^{\mathrm{n}}, \tau, \Sigma\right)$. The significance of such introduction is that the measure space $\left(\mathrm{R}^{\mathrm{n}}, \tau, \Sigma, \mu_{\mathrm{A}}\right)$ will be covered by atomic Borel sets that are countable. This has an advantage in the present study in terms of extension of usual topological properties on $\left(\mathrm{R}^{\mathrm{n}}, \tau\right)$ into an atomic measure space $\left(\mathrm{R}^{\mathrm{n}}, \tau, \Sigma, \mu_{\mathrm{A}}\right)$. These extended properties are redefined in terms of atomic measure $\square_{A}$ and it will be shown that some extended topological properties on $\left(\mathrm{R}^{\mathrm{n}}, \tau, \Sigma, \mu_{\mathrm{A}}\right)$ satisfy measure invariant condition under measure transformation. The interesting feature of this research is that the atomic measure space $\left(\mathrm{R}^{\mathrm{n}}, \tau, \Sigma, \mu_{\mathrm{A}}\right)$ carries two structure one is topological and another is $\sigma-$ algebra on which atomic measure $\mathrm{Q}_{\mathrm{A}}$ is well defined. In this paper it will be shown that the extended topological properties on atomic measure space $\left(\mathrm{R}^{\mathrm{n}}, \tau, \Sigma, \mu_{\mathrm{A}}\right)$ are not only invariant under homeomorphism but they are invariant under measure transformation also. Keeping this approach in the mind S. C. P. Halakatti has developed the following concepts and results for some future applications. This conceptual framework will be used to built new structures on measure manifold, introduced by S. C. P. Halakatti [1], on which geometrical properties can be studied.

In this section let us re- designate some of basic concepts of topological space such as open sets, closed sets, $\mathrm{T}_{0}, \mathrm{~T}_{1}$ and $\mathrm{T}_{2}$ as atomic Borel open sets/closed sets and $\mathrm{AT}_{0}, \mathrm{AT}_{1}, \mathrm{AT}_{2}$, on atomic measure space respectively.

\subsection{Definition: Neighborhood in Measure Space $\left(R^{n}, \tau, \Sigma, \mu\right)$}

Given a measure space $\left(\mathrm{R}^{\mathrm{n}}, \tau, \Sigma, \mu\right)$. Then for any point $\mathrm{p} \in\left(\mathrm{R}^{\mathrm{n}}, \tau, \Sigma, \mu\right) \exists \mathrm{q} \neq \mathrm{p} \in\left(\mathrm{R}^{\mathrm{n}}, \tau, \Sigma, \mu\right)$ such that $\mathrm{d}(\mathrm{p}, \mathrm{q})<\delta$, i.e., $\left\{\mathrm{q} \in \mathrm{R}^{\mathrm{n}}: \mathrm{d}(\mathrm{p}, \mathrm{q})<\delta\right\}=\mathrm{N}_{\delta}(\mathrm{p})$ satisfying $\mu\left(\mathrm{N}_{\delta}(\mathrm{p})\right)>0$.

Then $\mathrm{N}_{\delta}(\mathrm{p})$ is called a neighborhood of $\mathrm{p}$ in measure space $\left(\mathrm{R}^{\mathrm{n}}, \tau, \Sigma, \mu\right)$. 


\subsection{Definition: Atomic Borel Open Set}

Let $\left(\mathrm{R}^{\mathrm{n}}, \tau, \Sigma, \mu\right)$ be a measure space and $\mathrm{A}$ be a subset of $\left(\mathrm{R}^{\mathrm{n}}, \tau, \Sigma, \mu_{\mathrm{A}}\right)$, then $\mathrm{A}$ is called atomic Borel open set if $\exists \mathrm{N}_{\delta}(\mathrm{p})$ for every $\mathrm{p}$ in $\left(\mathrm{R}^{\mathrm{n}}, \tau, \Sigma, \mu_{\mathrm{A}}\right)$ such that $\mathrm{p} \in \mathrm{N}_{\delta}(\mathrm{p}) \subset$ A satisfying :

i) $\mu(\mathrm{A})>0$ and

ii)has either $\mu\left(\mathrm{N}_{\delta}(\mathrm{p})\right)=0$ or $\mu\left(\mathrm{N}_{\delta}(\mathrm{p})\right)=\mu(\mathrm{A})$.

We designate the Atomic measure as $\mu_{\mathrm{A}}$.

\subsection{Definition: Atomic Borel Closed Set}

Let $\left(\mathrm{R}^{\mathrm{n}}, \tau, \Sigma, \mu\right)$ be a measure space. The subset $\mathrm{F}$ of $\left(\mathrm{R}^{\mathrm{n}}, \tau, \Sigma, \mu_{\mathrm{A}}\right)$ is called atomic Borel closed set in $\left(\mathrm{R}^{\mathrm{n}}, \tau, \Sigma, \mu_{\mathrm{A}}\right)$ if $\exists \mathrm{N}_{\delta}(\mathrm{p})$ for every $\mathrm{p}$ in $\left(\mathrm{R}^{\mathrm{n}}, \tau, \Sigma, \mu_{\mathrm{A}}\right)$ such that

$\mathrm{N}_{\delta}^{\prime}(\mathrm{p}) \cap \mathrm{F} \neq \varnothing$ satisfying :

i) $\mu(\mathrm{F})>0$ and

ii)has either $\mu\left(\mathrm{N}_{\delta}(\mathrm{p})\right)=0$ or $\mu\left(\mathrm{N}_{\delta}(\mathrm{p})\right)=\mu(\mathrm{F})$.

We designate the Atomic measure as $\mu_{\mathrm{A}}$.

Note:

1) In above definitions $A$ is a subset of atomic measure space $\left(R^{n}, \tau, \Sigma, \mu_{A}\right)$ we mean

$\mathrm{A}=\left(\mathrm{A}, \tau / \mathrm{A}, \Sigma / \mathrm{A}, \mu_{\mathrm{A} /} \mathrm{A}\right)$ similarly $\mathrm{B}=\left(\mathrm{B}, \tau / \mathrm{B}, \Sigma / \mathrm{B}, \mu_{\mathrm{A} /} \mathrm{B}\right)$

2)Now onwards, whenever we mention any open/closed subsets like $C, D, E$ and $F$ of atomic measure space $\left(R^{n}\right.$ $\left., \tau, \Sigma, \mu_{\mathrm{A}}\right)$, we mean $\mathrm{C}=\left(\mathrm{C}, \tau / \mathrm{C}, \Sigma / \mathrm{C}, \mu_{\mathrm{A}} / \mathrm{C}\right)$ and $\mathrm{D}=\left(\mathrm{D}, \tau / \mathrm{D}, \Sigma / \mathrm{D}, \mu_{\mathrm{A}} / \mathrm{D}\right)$ similarly $\mathrm{E}$ and $\mathrm{F}$.

\subsection{Definition: Atomic $\mathrm{T}_{\mathbf{0}}$ - Space / $\mathrm{AT}_{\mathbf{0}}$ - Space}

An atomic measure space $\left(\mathrm{R}^{\mathrm{n}}, \tau, \Sigma, \mu_{\mathrm{A}}\right)$ is said to be an atomic $\mathrm{T}_{0}$ - Space if for every $\mathrm{p}, \mathrm{q} \in\left(\mathrm{R}^{\mathrm{n}}, \tau, \Sigma\right.$, $\mu_{\mathrm{A}}$ ) with $\mathrm{q} \neq \mathrm{p} \exists$ atomic Borel open sets $\mathrm{A}, \mathrm{B} \in \Sigma$ such that $\mathrm{p} \in \mathrm{A}$ and $\mathrm{q} \in \mathrm{B}$ and $\mathrm{A} \cap \mathrm{B}=\varnothing$ satisfying the atomic measure conditions :

i) for $\mathrm{p} \in \mathrm{A} \exists \mathrm{C} \in \Sigma$, $\mathrm{C} \subset \mathrm{A}$ and has either $\mu_{\mathrm{A}}(\mathrm{C})=0$ or $\mu_{\mathrm{A}}(\mathrm{C})=\mu_{\mathrm{A}}(\mathrm{A})$

ii) for $\mathrm{q} \in \mathrm{B} \exists \mathrm{D} \in \Sigma$, $\mathrm{D} \subset \mathrm{B}$ and has either $\mu_{\mathrm{A}}(\mathrm{D})=0$ or $\mu_{\mathrm{A}}(\mathrm{D})=\mu_{\mathrm{A}}(\mathrm{B})$ and $\mu_{\mathrm{A}}(\mathrm{A} \cap \mathrm{B})=\mu_{\mathrm{A}}(\varnothing)=0$.

\subsection{Definition: Atomic $\mathrm{T}_{1}$ - Space / $\mathrm{AT}_{1}$ - Space}

An atomic measure space $\left(\mathrm{R}^{\mathrm{n}}, \tau, \Sigma, \mu_{\mathrm{A}}\right)$ is said to be an atomic $\mathrm{T}_{1}-$ Space if for every $\mathrm{p}, \mathrm{q} \in\left(\mathrm{R}^{\mathrm{n}}, \tau, \Sigma\right.$, $\mu_{\mathrm{A}}$ ) with $\mathrm{q} \neq \mathrm{p} \exists$ atomic Borel open sets $\mathrm{A}, \mathrm{B} \in \Sigma$ such that $\mathrm{p} \in \mathrm{A}$ and $\mathrm{p} \notin \mathrm{Band} \mathrm{q} \in \mathrm{B}$ and $\mathrm{A} \cap \mathrm{B}=\varnothing$ satisfying the atomic measure conditions :

i) for $p \in A \exists C \in \Sigma, C \subset A$ and has either $\mu_{A}(C)=0$ or $\mu_{A}(C)=\mu_{A}(A)$

ii) for $\mathrm{q} \in \mathrm{B} \exists \mathrm{D} \in \Sigma, \mathrm{D} \subset \mathrm{B}$ and has either $\mu_{\mathrm{A}}(\mathrm{D})=0$ or $\mu_{\mathrm{A}}(\mathrm{D})=\mu_{\mathrm{A}}(\mathrm{B})$ and $\mu_{\mathrm{A}}(\mathrm{A} \cap \mathrm{B})=\mu_{\mathrm{A}}(\varnothing)=0$.

Note: We know that the measure of any singleton set is zero.

3.6 Definition: Atomic Hausdorff / Atomic $\mathbf{T}_{2}$ - Space $\left(\mathrm{AT}_{2}-\mathrm{Space}\right)$

An atomic measure space $\left(\mathrm{R}^{\mathrm{n}}, \tau, \Sigma, \mu_{\mathrm{A}}\right)$ is said to be an atomic $\mathrm{T}_{2}$ - Space if for every

$\mathrm{p}, \mathrm{q} \in\left(\mathrm{R}^{\mathrm{n}}, \tau, \Sigma, \mu_{\mathrm{A}}\right)$ with $\mathrm{q} \neq \mathrm{p} \exists$ atomic Borel open sets $\mathrm{A}, \mathrm{B} \in \Sigma$ such that $\mathrm{p} \in \mathrm{A}$ and $\mathrm{p} \notin \mathrm{B}, \mathrm{q} \in \mathrm{B}$ and $\mathrm{q} \notin \mathrm{A}$ such that $\mathrm{A} \cap \mathrm{B}=\varnothing$ satisfying the atomic measure conditions :

i) for $p \in A$ and $p \notin B \exists C \in \Sigma, C \subset A$ and has either $\mu_{A}(C)=0$ or $\mu_{A}(C)=\mu_{A}(A)$

ii) for $\mathrm{q} \in \mathrm{B}$ and $\mathrm{q} \notin \mathrm{A} \exists \mathrm{D} \in \Sigma, \mathrm{D} \subset \mathrm{B}$ and has either $\mu_{\mathrm{A}}(\mathrm{D})=0$ or $\mu_{\mathrm{A}}(\mathrm{D})=\mu_{\mathrm{A}}(\mathrm{B})$ and $\mu_{\mathrm{A}}(\mathrm{A} \cap \mathrm{B})=\mu_{\mathrm{A}}(\varnothing)=0$.

Note: We know that the measure of any singleton set is zero.

\section{Example:}

1)Let $X=\{a, b, c, d\}$

$\tau(\mathrm{X})=\{\mathrm{X}, \varnothing,\{\mathrm{a}, \mathrm{b}\},\{\mathrm{c}, \mathrm{d}\}\}$ be a topology on $\mathrm{X}$.

$\tau^{\prime}(X)=\{\varnothing, X,\{c, d\},\{a, b\}\}$ be complement of $\tau$.

Let $\mathrm{a}, \mathrm{c} \in \mathrm{X}$ then $\exists$ open sets $\mathrm{A}=\{\mathrm{a}, \mathrm{b}\}$ and $\mathrm{B}=\{\mathrm{c}, \mathrm{d}\} \in \tau$ such that $\mathrm{a} \in \mathrm{A}, \mathrm{c} \in \mathrm{B}$ and $\mathrm{A} \cap \mathrm{B}=\emptyset$.

$\Rightarrow(X, \tau)$ is a Hausdorff space.

Now consider the Sigma algebra generated by open sets.

$\Sigma(\mathrm{X})=\{\mathrm{X}, \varnothing,\{\mathrm{a}, \mathrm{b}\},\{\mathrm{c}, \mathrm{d}\}\}$

Consider a, $\mathrm{c} \in \mathrm{X}$ with $\mathrm{a} \neq \mathrm{c} \exists$ atomic Borel open sets $\mathrm{A}=\{\mathrm{a}, \mathrm{b}\}$ and $\mathrm{B}=\{\mathrm{c}, \mathrm{d}\}$ such that $\mathrm{a} \in \mathrm{A}$ and $\mathrm{c} \in \mathrm{B}$ satisfying the atomic measure conditions:

I) for $\mathrm{a} \in \mathrm{A} \exists \mathrm{C}=\{\mathrm{a}, \mathrm{b}\} \in \Sigma, \mathrm{C} \subset \mathrm{A}$ and has either

i) $\mu_{\mathrm{A}}(\mathrm{C})=0$ 
$\Rightarrow$ i.e., $\mu_{A}(\{a, b\})=0$

but it is not true

\section{OR}

ii) $\mu_{\mathrm{A}}(\mathrm{C})=\mu_{\mathrm{A}}(\mathrm{A})$

i.e., $\mu_{A}(\{a, b\})=\mu_{A}(\{a, b\})$

which is obvious

Therefore I is true.

II) for $\mathrm{c} \in \mathrm{B} \exists \mathrm{D}=\{\mathrm{c}, \mathrm{d}\} \in \Sigma, \mathrm{D} \subset \mathrm{B}$ and has either

i) $\mu_{A}(D)=0$

$\Rightarrow$ i.e., $\mu_{A}(\{c, d\})=0$

but it is not true

\section{OR}

ii) $\mu_{A}(D)=\mu_{A}(B)$

i.e., $\mu_{A}(\{c, d\})=\mu_{A}(\{c, d\})$

which is obvious

Therefore II is also true.

Also $\mu_{\mathrm{A}}(\mathrm{A} \cap \mathrm{B})=\mu_{\mathrm{A}}(\{\mathrm{a}, \mathrm{b}\} \cap\{\mathrm{c}, \mathrm{d}\})=\mu_{\mathrm{A}}(\varnothing)=0$.

$\Rightarrow\left(X, \tau, \Sigma, \mu_{A}\right)$ is atomic Hausdorff space.

\section{Example:}

2) Let us consider a counter example where atomic Hausdorff property is not valid.

Let $X=\{a, b, c\}$

$\tau(X)=\{X, \varnothing,\{a, b\},\{c\}\}$ be a topology on $X$.

$\tau^{\prime}(X)=\{\varnothing, X,\{c\},\{a, b\}\}$ be complement of $\tau$.

Consider $\mathrm{a}, \mathrm{c} \in \mathrm{X}$ then $\exists$ open sets $\mathrm{A}=\{\mathrm{a}, \mathrm{b}\}$ and $\mathrm{B}=\{\mathrm{c}\} \in \tau$ such that $\mathrm{a} \in \mathrm{A}, \mathrm{c} \in \mathrm{B}$ and $\mathrm{A} \cap \mathrm{B}=\emptyset$.

$\Rightarrow(X, \tau)$ is a Hausdorff space.

Now $\Sigma(\mathrm{X})=\{\mathrm{X}, \emptyset,\{\mathrm{a}, \mathrm{b}\},\{\mathrm{c}\}\}$

Consider $\mathrm{a}, \mathrm{c} \in \mathrm{X}$ with $\mathrm{a} \neq \mathrm{c} \nexists$ atomic Borel open sets $\mathrm{A}=\{\mathrm{a}, \mathrm{b}\}$ and $\mathrm{B}=\{\mathrm{c}\}$ such that $\mathrm{a} \in \mathrm{A}$ and $\mathrm{c} \in \mathrm{B}$ and $\mu_{\mathrm{A}}(\mathrm{A} \cap \mathrm{B})=0$.

Because $\mu_{A}(B)$ must be greater than zero for $B$ to be an atom but here $B=\{c\}$ and we know that measure of singleton set is zero i.e., $\mu_{A}(B)=\mu_{A}(\{c\})=0$. Therefore there does not exists atomic Borel open set with $\mu_{\mathrm{A}}(\mathrm{B})>0$.

Therefore $\left(\mathrm{X}, \tau, \Sigma, \mu_{\mathrm{A}}\right)$ is not atomic Hausdorff space.

\subsection{Definition Atomic Regular Space / AR-space}

An atomic measure space $\left(\mathrm{R}^{\mathrm{n}}, \tau, \Sigma, \mu_{\mathrm{A}}\right)$ is said to be atomic regular, if given any point $\mathrm{p}$ and closed set $\mathrm{F}$ in $\left(\mathrm{R}^{\mathrm{n}}, \tau, \Sigma, \mu_{\mathrm{A}}\right)$ such that $\mathrm{p} \notin \mathrm{F}$, there exists atomic Borel open sets $\mathrm{A}$ and $\mathrm{B} \in \Sigma$ such that $\mathrm{p} \in \mathrm{A}, \mathrm{F} \subset \mathrm{B}$ and $\mathrm{A} \cap \mathrm{B}=0$ satisfying the atomic measure conditions:

i) for $p \in A \exists C \in \Sigma, C \subset A$ and has either $\mu_{A}(C)=0$ or $\mu_{A}(C)=\mu_{A}(A)$.

ii) for $F \subset B \exists D \in \Sigma, F \subset B$ and $D \subset B$ and has either $\mu_{A}(D)=0$ or $\mu_{A}(D)=\mu_{A}(B)$ and $\mu_{A}(A \cap B)=\mu_{A}(\varnothing)=0$.

\section{Example:}

1) Let $X=\{a, b, c, d, e\}$

$\tau(X)=\{X, \varnothing,\{a, b\},\{c, d\},\{e\},\{a, b, e\},\{c, d, e\}\}$ be a topology on $X$.

$\tau^{\prime}(X)=\{\varnothing, X,\{c, d, e\},\{a, b, e\},\{a, b, c, d\},\{c, d\},\{a, b\}\}$ be complement of $\tau$.

Consider a point ' $a$ ' and a closed set $\mathrm{F}=\{\mathrm{c}, \mathrm{d}, \mathrm{e}\} \in \mathrm{X}$ such that $\mathrm{a} \notin \mathrm{F}=\{\mathrm{c}, \mathrm{d}, \mathrm{e}\}$ then $\exists$ open sets $\mathrm{A}=\{\mathrm{a}, \mathrm{b}\}$ and $\mathrm{B}=\{\mathrm{c}, \mathrm{d}, \mathrm{e}\}$ and $\mathrm{A} \cap \mathrm{B}=\emptyset$.

$\Rightarrow(X, \tau)$ is a regular space.

Now consider the Sigma algebra generated by open sets.

$\Sigma(\mathrm{X})=\{\mathrm{X}, \emptyset, \mathrm{a}, \mathrm{b}\},\{\mathrm{c}, \mathrm{d}\},\{\mathrm{e}\},\{\mathrm{a}, \mathrm{b}, \mathrm{e}\},\{\mathrm{c}, \mathrm{d}, \mathrm{e}\},\{\mathrm{a}, \mathrm{b}, \mathrm{c}, \mathrm{d}\}\}$

Let a point ' $\mathrm{a}$ ' and a closed set $\mathrm{F}=\{\mathrm{c}, \mathrm{d}, \mathrm{e}\} \in \mathrm{X}$ such that $\mathrm{a} \notin \mathrm{F}=\{\mathrm{c}, \mathrm{d}, \mathrm{e}\}$ then $\exists$ atomic Borel open sets $\mathrm{A}=$ $\{\mathrm{a}, \mathrm{b}\}$ and $\mathrm{B}=\{\mathrm{c}, \mathrm{d}, \mathrm{e}\}$ such that $\mathrm{a} \in \mathrm{A}, \mathrm{F} \subset \mathrm{B}$ and satisfying the atomic measure conditions:

I)for $\mathrm{a} \in \mathrm{A} \exists \mathrm{C}=\{\mathrm{a}, \mathrm{b}\} \in \Sigma, \mathrm{C} \subset \mathrm{A}$ and has either

i) $\mu_{A}(C)=0$

$\Rightarrow$ i.e., $\mu_{\mathrm{A}}(\{\mathrm{a}, \mathrm{b}\})=0$

but it is not true

OR

ii) $\mu_{\mathrm{A}}(\mathrm{C})=\mu_{\mathrm{A}}(\mathrm{A})$

i.e., $\mu_{A}(\{a, b\})=\mu_{A}(\{a, b\})$ 
which is obvious

Therefore I is true.

II) for $\mathrm{F} \subset \mathrm{B} \exists \mathrm{D}=\{\mathrm{c}, \mathrm{d}, \mathrm{e}\} \in \Sigma, \mathrm{F} \subset \mathrm{D}$ and $\mathrm{D} \subset \mathrm{B}$ has either

i) $\mu_{\mathrm{A}}(\mathrm{D})=0$

$\Longrightarrow$ i.e., $\mu_{\mathrm{A}}(\{\mathrm{c}, \mathrm{d}, \mathrm{e}\})=0$

but it is not true

OR

ii) $\mu_{\mathrm{A}}(\mathrm{D})=\mu_{\mathrm{A}}(\mathrm{B})$

i.e., $\mu_{A}(\{c, d, e\})=\mu_{A}(\{c, d, e\})$

which is obvious

Therefore II is also true.

Also $\mu_{A}(A \cap B)=\mu_{A}(\{a, b\} \cap\{c, d, e\})=\mu_{A}(\varnothing)=0$.

$\Rightarrow\left(\mathrm{X}, \tau, \Sigma, \mu_{\mathrm{A}}\right)$ is atomic regular space.

\section{Example:}

2) Let us consider a counter example where atomic regular property is not valid.

Let $X=\{a, b, c, d, e\}$

$\tau(X)=\{X, \varnothing,\{a, b, c, d\},\{b, c, d\},\{e\},\{b, c, d, e\}\}$ be a topology on $X$.

$\tau^{\prime}(\mathrm{X})=\{\varnothing, \mathrm{X},\{\mathrm{e}\},\{\mathrm{a}, \mathrm{e}\},\{\mathrm{a}, \mathrm{b}, \mathrm{c}, \mathrm{d}\},\{\mathrm{a}\}\}$ be complement of $\tau$.

Consider a point 'e' and a closed set $\mathrm{F}=\{\mathrm{a}, \mathrm{b}, \mathrm{c}, \mathrm{d}\} \in \mathrm{X}$ such that $\mathrm{e} \notin \mathrm{F}=\{\mathrm{a}, \mathrm{b}, \mathrm{c}, \mathrm{d}\}$ then $\exists$ open sets $\mathrm{A}=\{\mathrm{e}\}$ and $\mathrm{B}=\{\mathrm{a}, \mathrm{b}, \mathrm{c}, \mathrm{d}\}$ such that $\mathrm{e} \in \mathrm{A}, \mathrm{F} \subset \mathrm{B}$ and $\mathrm{A} \cap \mathrm{B}=\varnothing$.

$\Rightarrow(X, \tau)$ is a regular space.

Consider $\Sigma(\mathrm{X})=\{\mathrm{X}, \emptyset,\{\mathrm{e}\},\{\mathrm{a}\},\{\mathrm{a}, \mathrm{e}\},\{\mathrm{b}, \mathrm{c}, \mathrm{d}\},\{\mathrm{a}, \mathrm{b}, \mathrm{c}, \mathrm{d}\},\{\mathrm{b}, \mathrm{c}, \mathrm{d}, \mathrm{e}\}\}$

Let a point ' $a$ ' and closed set $\mathrm{F}=\{\mathrm{c}, \mathrm{d}, \mathrm{e}\} \in \mathrm{X}$ such that $\mathrm{e} \notin \mathrm{F}=\{\mathrm{a}, \mathrm{b}, \mathrm{c}, \mathrm{d}\} \nexists$ atomic Borel open sets $\mathrm{A}=\{\mathrm{e}\}$ and $\mathrm{B}=\{\mathrm{a}, \mathrm{b}, \mathrm{c}, \mathrm{d}\}$ such that $\mathrm{e} \in \mathrm{A}$ and $\mathrm{F} \subset \mathrm{B}$ and $\mu_{\mathrm{A}}(\mathrm{A} \cap \mathrm{B})=0$.

Because $\mu_{\mathrm{A}}(\mathrm{A})$ must be greater than zero for $\mathrm{A}$ to be an atom but here $\mathrm{A}=\{\mathrm{e}\}$ and we know that measure of singleton set is zero i.e., $\mu_{\mathrm{A}}(\mathrm{A})=\mu_{\mathrm{A}}(\{\mathrm{e}\})=0$. Therefore there does not exists atomic Borel open set with $\mu_{\mathrm{A}}(\mathrm{A})>0$.

Therefore $\left(\mathrm{X}, \tau, \Sigma, \mu_{\mathrm{A}}\right)$ is not atomic regular space.

\subsection{Definition: Atomic $\mathbf{T}_{3}$ - Space / $\mathbf{A T}_{3}$ - Space} $\mathrm{T}_{1}$ - Space.

An atomic measure space $\left(\mathrm{R}^{\mathrm{n}}, \tau, \Sigma, \mu_{\mathrm{A}}\right)$ is said to be atomic $\mathrm{T}_{3}$ - Space if it is atomic regular and atomic

\subsection{Definition: Completely Atomic Regular Space / CAR - Space}

An atomic measure space $\left(\mathrm{R}^{\mathrm{n}}, \tau, \Sigma, \mu_{\mathrm{A}}\right)$ is said to be completely atomic regular space if for any point $\mathrm{p}$ $\in \mathrm{A} \subset\left(\mathrm{R}^{\mathrm{n}}, \tau, \Sigma, \mu_{\mathrm{A}}\right)$ and atomic Borel closed set $\mathrm{F} \subset \mathrm{B}$ not containing $\mathrm{p}$, there exists a continuous function $\mathrm{f}:\left(\mathrm{R}^{\mathrm{n}}, \tau, \Sigma, \mu_{\mathrm{A}}\right) \rightarrow[0,1]$ such that i) $\forall \mathrm{p} \in \mathrm{A} \subset\left(\mathrm{R}^{\mathrm{n}}, \tau, \Sigma, \mu_{\mathrm{A}}\right) \exists \mathrm{C} \in \Sigma, \mathrm{C} \subset \mathrm{A}$ and has either $\mu_{\mathrm{A}}(\mathrm{C})=0$ or $\mu_{\mathrm{A}}(\mathrm{C})=\mu_{\mathrm{A}}(\mathrm{A})$ then $\mathrm{f}(\mathrm{p})=0$.

ii) $\forall \mathrm{q} \in \mathrm{F} \subset \mathrm{B} \exists \mathrm{D} \in \Sigma, \mathrm{F} \subset \mathrm{B}$ and $\mathrm{D} \subset \mathrm{B}$ and has either $\mu_{\mathrm{A}}(\mathrm{D})=0$ or $\mu_{\mathrm{A}}(\mathrm{D})=\mu_{\mathrm{A}}(\mathrm{B})$ then $\mathrm{f}(\mathrm{q})=1$.

\subsection{Definition: Atomic Tychonoff Space / Atomic $\mathbf{T}_{3_{1 / 2}}$ Space}

An atomic measure space $\left(\mathrm{R}^{\mathrm{n}}, \tau, \Sigma, \mu_{\mathrm{A}}\right)$ is said to be atomic Tychonoff or $\mathrm{T}_{3_{1 / 2}}$ space if it is completely atomic regular and atomic $\mathrm{T}_{1}$ - Space.

\subsection{Definition: Atomic Normal Space / AN - Space}

An atomic measure space $\left(\mathrm{R}^{\mathrm{n}}, \tau, \Sigma, \mu_{\mathrm{A}}\right)$ is said to be atomic normal space if for every two disjoint closed sets $\mathrm{E}$ and $\mathrm{F}$ of $\mathrm{R}^{\mathrm{n}}$ there exists atomic Borel open sets $\mathrm{A}$ and $\mathrm{B}$ such that $\mathrm{E} \subset \mathrm{A}, \mathrm{F} \subset \mathrm{B}$ and $\mathrm{A} \cap \mathrm{B}=\varnothing$ satisfying the atomic measure conditions:

i)for $\mathrm{E} \subset \mathrm{A} \exists \mathrm{C} \in \Sigma, \mathrm{E} \subset \mathrm{C}$ and $\mathrm{C} \subset \mathrm{A}$ and has either $\mu_{\mathrm{A}}(\mathrm{C})=0$ or $\mu_{\mathrm{A}}(\mathrm{C})=\mu_{\mathrm{A}}(\mathrm{A})$

ii)for $\mathrm{F} \subset \mathrm{B} \exists \mathrm{D} \in \Sigma, \mathrm{F} \subset \mathrm{D}$ and $\mathrm{D} \subset \mathrm{B}$ and has either $\mu_{\mathrm{A}}(\mathrm{D})=0$ or $\mu_{\mathrm{A}}(\mathrm{D})=\mu_{\mathrm{A}}(\mathrm{B})$ and $\mu_{\mathrm{A}}(\mathrm{A} \cap \mathrm{B})=\mu_{\mathrm{A}}(\varnothing)=0$.

3.12 Definition: Atomic $\mathbf{T}_{4}$ - Space / $\mathbf{A T}_{\mathbf{4}}$ - Space

An atomic measure space $\left(\mathrm{R}^{\mathrm{n}}, \tau, \Sigma, \mu_{\mathrm{A}}\right)$ is said to be atomic $\mathrm{T}_{4}$ - Space if it is atomic normal and atomic $\mathrm{T}_{1}$ Space. 


\subsection{Definition: Atomic Completely Normal Space / ACN - Space}

An atomic measure space $\left(\mathrm{R}^{\mathrm{n}}, \tau, \Sigma, \mu_{\mathrm{A}}\right)$ is said to be atomic completely normal space if for every two mutually atomic separated sets $\mathrm{E}, \mathrm{F} \in\left(\mathrm{R}^{\mathrm{n}}, \tau, \Sigma, \mu_{\mathrm{A}}\right)$ there exists atomic Borel open sets $\mathrm{A}, \mathrm{B} \in \Sigma$ such that $\mathrm{E} \subset$ $\mathrm{A}, \mathrm{F} \subset \mathrm{B}$ and $\mathrm{A} \cap \mathrm{B}=\emptyset$ satisfying the atomic measure conditions:

i) for $E \subset A \exists C \in \Sigma, E \subset C$ and $C \subset A$ and has either $\mu_{A}(C)=0$ or $\mu_{A}(C)=\mu_{A}(A)$

ii) for $\mathrm{F} \subset \mathrm{B} \exists \mathrm{D} \in \Sigma, \mathrm{F} \subset \mathrm{D}$ and $\mathrm{D} \subset \mathrm{B}$ and has either $\mu_{\mathrm{A}}(\mathrm{D})=0$ or $\mu_{\mathrm{A}}(\mathrm{D})=\mu_{\mathrm{A}}(\mathrm{B})$ and $\mu_{\mathrm{A}}(\mathrm{A} \cap \mathrm{B})=\mu_{\mathrm{A}}(\varnothing)=0$.

\subsection{Definition: Atomic $\mathbf{T}_{5}$ - Space / $\mathbf{A T}_{5}$ - Space}

An atomic measure space $\left(\mathrm{R}^{\mathrm{n}}, \tau, \Sigma, \mu_{\mathrm{A}}\right)$ is said to be atomic $\mathrm{T}_{5}$ - Space if it is atomic completely normal and atomic $\mathrm{T}_{1}$ - Space.

A measure space $\left(\mathrm{R}^{\mathrm{n}}, \tau, \Sigma, \mu_{\mathrm{A}}\right)$ carries two mathematical structures, the topological structure induced by open subsets of $\mathrm{R}^{\mathrm{n}}$ and $\sigma$ - algebraic structure induced by Borel sets generated by open subsets of $\left(\mathrm{R}^{\mathrm{n}}, \tau\right)$. We will show in this paper that these two structures enriches a measure space $\left(\mathrm{R}^{\mathrm{n}}, \tau, \Sigma, \mu\right)$ in the sense that the topological properties that are invariant under topological homeomorphism are also invariant under measure invariant transformation, where the measure of Borel sets involved in generating $\sigma$ - algebraic structure on $\left(\mathrm{R}^{\mathrm{n}}, \tau, \Sigma\right)$ are measurable and can be quantified. Such results have deeper implications in the study of measure manifold introduced by S. C. P. Halakatti [1]. On the measure manifold (M, $\tau, \Sigma, \mu)$ which is modeled on $\left(\mathrm{R}^{\mathrm{n}}, \tau, \Sigma, \mu\right)$, if the topological properties like $\mathrm{T}_{0}, \mathrm{~T}_{1}, \mathrm{~T}_{2}, \mathrm{~T}_{3}, \mathrm{~T}_{3_{1 / 2}}, \mathrm{~T}_{4}$ and $\mathrm{T}_{5}$ are invariant under topological homeomorphism then it can be shown that these properties are invariant under measure invariant transformation. The measure manifold smoothly displays the interesting intrinsic property, i.e., on such manifolds topologically invariant properties are also measure invariant. The measure manifold confirms the measure invariance of topological properties.

In this paper we consider the Hausdorff property which is invariant under measure invariant transformation on $\left(\mathrm{R}^{\mathrm{n}}, \tau, \Sigma, \mu\right)$. The measure invariance of regular, completely regular, normal and completely normal will be considered and extended on measure manifolds in our future work. The following proposition has an important implication in the study of measure manifolds.

Proposition 1. For every topological homeomorphism with reference to topological structure $\tau_{1}$ on measure space $\left(\mathrm{R}^{\mathrm{n}}, \tau_{1}, \Sigma_{1}, \mu_{1}\right)$, i.e., $\mathrm{T}:\left(\mathrm{R}^{\mathrm{n}}, \tau_{1}, \Sigma_{1}, \mu_{1}\right) \rightarrow\left(\mathrm{R}^{\mathrm{m}}, \tau_{2}, \Sigma_{2}, \mu_{2}\right)$ there exists a measure invariant transformation with reference to $\sigma$ - algebraic structure $\Sigma_{1}$ on a measure space $\left(\mathrm{R}^{\mathrm{n}}, \tau_{1}, \Sigma_{1}, \mu_{1}\right)$.

Proof : Let $\left(\mathrm{R}^{\mathrm{n}}, \tau_{1}, \Sigma_{1}, \mu_{1}\right)$ be a measure space such that $\exists$ a homeomorphism

$\mathrm{T}:\left(\mathrm{R}^{\mathrm{n}}, \tau_{1}, \Sigma_{1}, \mu_{1}\right) \rightarrow\left(\mathrm{R}^{\mathrm{m}}, \tau_{2}, \Sigma_{2}, \mu_{2}\right)$

with reference to topological structure $\tau_{1}$ on $\mathrm{R}^{\mathrm{n}}$.

i.e., $\mathrm{T}$ is one -one, onto and $\mathrm{T}, \mathrm{T}^{-1}$ are continuous.

A $\sigma$ - algebraic structure on $\left(\mathrm{R}^{\mathrm{n}}, \tau_{1}\right)$ transforms a topological space into a measure space $\left(\mathrm{R}^{\mathrm{n}}, \tau_{1}, \Sigma_{1}, \mu_{1}\right)$.

Now we will show that for every homeomorphism on $\left(\mathrm{R}^{\mathrm{n}}, \tau_{1}, \Sigma_{1}, \mu_{1}\right) \exists$ measure invariant transformation

$\mathrm{T}:\left(\mathrm{R}^{\mathrm{n}}, \tau_{1}, \Sigma_{1}, \mu_{1}\right) \rightarrow\left(\mathrm{R}^{\mathrm{m}}, \tau_{2}, \Sigma_{2}, \mu_{2}\right)$

is measurable and measure invariant.

Step-I:

Let us show that $\exists$ a map $\mathrm{T}:\left(\mathrm{R}^{\mathrm{n}}, \tau_{1}, \Sigma_{1}, \mu_{1}\right) \rightarrow\left(\mathrm{R}^{\mathrm{m}}, \tau_{2}, \Sigma_{2}, \mu_{2}\right)$

which is measurable and measure invariant.

Since $\mathrm{T}$ is homeomorphism

$\Rightarrow \mathrm{T}$ is continuous

$\Rightarrow$ for every open set $U \in \tau_{2} \exists \mathrm{T}^{-1}(\mathrm{U}) \in \tau_{1}$

since every open set $U \in \tau_{2}$ generates a Borel set $A \in \Sigma_{2}$ such that $A$ is measurable in $\left(\mathrm{R}^{\mathrm{m}}, \tau_{2}, \Sigma_{2}, \mu_{2}\right)$.

Therefore for every open set $U \in \tau_{2} \exists$ a measurable set $A \in \Sigma_{2}$, and for every open set $T^{-1}(U) \in \tau_{1}$ generates a borel set $\mathrm{T}^{-1}(\mathrm{~A}) \in \Sigma_{1}$.

Thus for every measurable set $\mathrm{A} \in \Sigma_{2} \exists$ a measurable set $\mathrm{T}^{-1}(\mathrm{~A}) \in \Sigma_{1}$.

$\Longrightarrow$ The continuous map T has induced a measurable transformation

$\mathrm{T}:\left(\mathrm{R}^{\mathrm{n}}, \tau_{1}, \Sigma_{1}, \mu_{1}\right) \rightarrow\left(\mathrm{R}^{\mathrm{m}}, \tau_{2}, \Sigma_{2}, \mu_{2}\right)$

Therefore $\mathrm{T}$ is measurable.

Step-II:

Also to show that $\mathrm{T}$ is measure invariant

Since $\mathrm{T}$ and $\mathrm{T}^{-1}$ are continuous

$\Rightarrow$ for every $U \in \tau_{2} \exists \mathrm{T}^{-1}(\mathrm{U}) \in \tau_{1}$ 
$\Rightarrow$ for every $\mathrm{A} \in \Sigma_{2} \exists \mathrm{T}^{-1}(\mathrm{~A}) \in \Sigma_{1}$ and both $\mathrm{A}$ and $\mathrm{T}^{-1}(\mathrm{~A})$ are measurable such that $\mu_{1}\left(\mathrm{~T}^{-1}(\mathrm{~A})\right)=\mu_{2}(\mathrm{~A})$.

$\Rightarrow \mathrm{T}$ is measure invariant.

Step-III: invariant.

Now we show that the map $T^{-1}:\left(\mathrm{R}^{\mathrm{m}}, \tau_{2}, \Sigma_{2}, \mu_{2}\right) \rightarrow\left(\mathrm{R}^{\mathrm{n}}, \tau_{1}, \Sigma_{1}, \mu_{1}\right)$ is also measurable and measure

As shown in steps I and II, in case of transformation $T:\left(\mathrm{R}^{\mathrm{n}}, \tau_{1}, \Sigma_{1}, \mu_{1}\right) \rightarrow\left(\mathrm{R}^{\mathrm{m}}, \tau_{2}, \Sigma_{2}, \mu_{2}\right)$

Similarly it can also be shown that $\exists \mathrm{T}^{-1}$ which is measurable and measure invariant.

Since $\mathrm{T}^{-1}$ is continuous

$\Longrightarrow$ for every open set $\mathrm{V} \in \tau_{1} \exists\left(\mathrm{T}^{-1}\right)^{-1}(\mathrm{~V}) \in \tau_{2}$

Since every open set $V \in \tau_{1}$, generates a Borel set $\mathrm{B} \in \Sigma_{1}$ such that $\mathrm{B}$ is measurable in $\left(\mathrm{R}^{\mathrm{n}}, \tau_{1}, \Sigma_{1}, \mu_{1}\right)$.

therefore for every open set $V \in \tau_{1} \exists$ a measurable set $B \in \Sigma_{1}$ and for every open set $\left(T^{-1}\right)^{-1}(V) \in \tau_{2}$ generates a Borel set $\left(\mathrm{T}^{-1}\right)^{-1}(\mathrm{~B}) \in \Sigma_{2}$.

$\Rightarrow \mathrm{T}^{-1}$ is measurable.

Step-IV:

Lastly, to show that $\mathrm{T}^{-1}$ is measure invariant

Since for every $V \in \tau_{1} \exists\left(T^{-1}\right)^{-1}(V) \in \tau_{2}$.

$\Rightarrow$ for every B $\in \Sigma_{1} \exists\left(\mathrm{T}^{-1}\right)^{-1}(\mathrm{~B}) \in \Sigma_{2}$ and both $\mathrm{B}$ and $\left(\mathrm{T}^{-1}\right)^{-1}(\mathrm{~B})$ are measurable such that $\mu_{2}\left(\left(\mathrm{~T}^{-1}\right)^{-1}(\mathrm{~B})\right)=$ $\mu_{1}(\mathrm{~B})$.

$\Rightarrow \mathrm{T}^{-1}$ is measure invariant.

Therefore for every topological homeomorphism between topological spaces there exists a measure invariant transformation on measure space $\left(\mathrm{R}^{\mathrm{n}}, \tau_{1}, \Sigma_{1}, \mu_{1}\right)$

Theorem 1. On a measure space $\left(\mathrm{R}^{\mathrm{n}}, \tau_{1}, \Sigma_{1}, \mu_{1}\right)$ if Hausdorff $\left(\mathrm{T}_{2}\right)$ property is a topological invariant under homeomorphism then it is invariant under measure transformation.

Proof : Let $\left(\mathrm{R}^{\mathrm{n}}, \tau_{1}\right)$ be a Hausdorff space such that there exists a homeomorphism $T:\left(\mathrm{R}^{\mathrm{n}}, \tau_{1}, \Sigma_{1}, \mu_{1}\right) \rightarrow$ $\left(\mathrm{R}^{\mathrm{m}}, \tau_{2}, \Sigma_{2}, \mu_{2}\right)$ then $\left(\mathrm{R}^{\mathrm{m}}, \tau_{2}, \Sigma_{2}, \mu_{2}\right)$ is also a Hausdorff space.

By proposition 1, for every topological homeomorphism between $\left(\mathrm{R}^{\mathrm{n}}, \tau_{1}, \Sigma_{1}, \mu_{1}\right)$ and $\left(\mathrm{R}^{\mathrm{m}}, \tau_{2}, \Sigma_{2}, \mu_{2}\right) \exists$ a measure invariant transformations

$\mathrm{T}:\left(\mathrm{R}^{\mathrm{n}}, \tau_{1}, \Sigma_{1}, \mu_{1}\right) \rightarrow\left(\mathrm{R}^{\mathrm{m}}, \tau_{2}, \Sigma_{2}, \mu_{2}\right)$

$$
\text { and } \mathrm{T}^{-1}:\left(\mathrm{R}^{\mathrm{m}}, \tau_{2}, \Sigma_{2}, \mu_{2}\right) \rightarrow\left(\mathrm{R}^{\mathrm{n}}, \tau_{1}, \Sigma_{1}, \mu_{1}\right)
$$

Such that $\mathrm{T}$ and $\mathrm{T}^{-1}$ are measurable and measure invariant.

Let $\mathrm{T}:\left(\mathrm{R}^{\mathrm{n}}, \tau_{1}, \Sigma_{1}, \mu_{1}\right) \rightarrow\left(\mathrm{R}^{\mathrm{m}}, \tau_{2}, \Sigma_{2}, \mu_{2}\right)$ be a homeomorphism.

Step-I:

Let us show that $\exists$ a map $T:\left(\mathrm{R}^{\mathrm{n}}, \tau_{1}, \Sigma_{1}, \mu_{1}\right) \rightarrow\left(\mathrm{R}^{\mathrm{m}}, \tau_{2}, \Sigma_{2}, \mu_{2}\right)$ which preserves the Hausdorff property under measure transformation. Since $\mathrm{R}^{\mathrm{m}}$ is Hausdorff space with reference to topological structure $\tau_{2}$, then for every points $\mathrm{p}, \mathrm{q} \in\left(\mathrm{R}^{\mathrm{m}}, \tau_{2}, \Sigma_{2}, \mu_{2}\right)$ with $\mathrm{p} \neq \mathrm{q} \exists$ open sets $\mathrm{U}$ and $\mathrm{V} \in \tau_{2}$ such that $\mathrm{p} \in \mathrm{A}, \mathrm{p} \notin \mathrm{B}$ and $\mathrm{q} \in \mathrm{B}, \mathrm{q} \notin \mathrm{A}$ such that $\mathrm{A} \cap \mathrm{B}=\emptyset$.

Since $\mathrm{T}$ is homeomorphism

$\Rightarrow \mathrm{T}$ is continuous

$\Longrightarrow$ for every points $\mathrm{p}, \mathrm{q} \in\left(\mathrm{R}^{\mathrm{m}}, \tau_{2}, \Sigma_{2}, \mu_{2}\right) \exists \mathrm{T}^{-1}(\mathrm{p})$ and $\mathrm{T}^{-1}(\mathrm{q}) \in\left(\mathrm{R}^{\mathrm{n}}, \tau_{1}, \Sigma_{1}, \mu_{1}\right)$.

Also $R^{n}$ is Hausdorff space with reference to topological structure $\tau_{1}$, then for every points $T^{-1}(p)$ and $T^{-1}(q) \in$ $\left(\mathrm{R}^{\mathrm{n}}, \tau_{1} \Sigma_{1}, \mu_{1}\right) \exists$ open sets $\mathrm{T}^{-1}(\mathrm{U})$ and $\mathrm{T}^{-1}(\mathrm{~V}) \in \tau_{1}$, such that $\mathrm{T}^{-1}(\mathrm{p}) \in \mathrm{T}^{-1}(\mathrm{U}), \mathrm{T}^{-1}(\mathrm{p}) \notin \mathrm{T}^{-1}(\mathrm{~V})$ and $\mathrm{T}^{-1}(\mathrm{q}) \in \mathrm{T}^{-1}(\mathrm{~V}), \mathrm{T}^{-1}(\mathrm{q}) \notin \mathrm{T}^{-1}(\mathrm{U})$ such that $\mathrm{T}^{-1}(\mathrm{U}) \cap \mathrm{T}^{-1}(\mathrm{~V})=\mathrm{T}^{-1}(\mathrm{U} \cap \mathrm{V})=\mathrm{T}^{-1}(\varnothing)=\varnothing$. [ $\mathrm{T}$ is onto in $\mathrm{R}^{\mathrm{m}}$ ]

since for every points $p, q \in\left(R^{m}, \tau_{2}, \Sigma_{2}, \mu_{2}\right) \exists$ open sets $U$ and $V \in \tau_{2}$ which generates corresponding Borel sets $\mathrm{A}, \mathrm{B} \in \Sigma_{2}$ such that $\mathrm{A}, \mathrm{B}$ are measurable in $\left(\mathrm{R}^{\mathrm{m}}, \tau_{2}, \Sigma_{2}, \mu_{2}\right)$.

Therefore for every $\mathrm{U}$ and $\mathrm{V} \in \tau_{2} \exists$ measurable sets $\mathrm{A}, \mathrm{B} \in \Sigma_{2}$ such that $\mathrm{p} \in \mathrm{A}, \mathrm{p} \notin \mathrm{B}$ and $\mathrm{q} \in \mathrm{B}, \mathrm{q} \notin \mathrm{A}$ and satisfy $\mu_{2}(\mathrm{~A} \cap \mathrm{B})=\mu_{2}(\varnothing)=0 \cdots \cdots \cdots(\mathrm{i})$

Similarly, for every $\mathrm{T}^{-1}(\mathrm{U})$ and $\mathrm{T}^{-1}(\mathrm{~V}) \in \tau_{1}$ generates a Borel sets $\mathrm{T}^{-1}(\mathrm{~A}), \mathrm{T}^{-1}(\mathrm{~B}) \in \Sigma_{1}$ such that $\mathrm{T}^{-1}(\mathrm{p}) \in \mathrm{T}^{-1}(\mathrm{~A}), \mathrm{T}^{-1}(\mathrm{p}) \notin \mathrm{T}^{-1}(\mathrm{~B})$ and $\mathrm{T}^{-1}(\mathrm{q}) \in \mathrm{T}^{-1}(\mathrm{~B}), \mathrm{T}^{-1}(\mathrm{q}) \notin \mathrm{T}^{-1}(\mathrm{~A})$ and satisfy $\mu_{1}\left(\mathrm{~T}^{-1}(\mathrm{~A})\right.$ $\left.\cap \mathrm{T}^{-1}(\mathrm{~B})\right)=\mu_{1}\left(\mathrm{~T}^{-1}(\mathrm{~A} \cap \mathrm{B})\right)=\mu_{1}(\varnothing)=0 \cdots \cdots \cdots($ ii $)$

$\Rightarrow \mathrm{T}$ is measurable.

Step-II:

Also to show that $\mathrm{T}$ preserves Hausdorff property under measure transformation.

Because $\mathrm{T}$ and $\mathrm{T}^{-1}$ are continuous

$\Rightarrow$ For every $\mathrm{U}, \mathrm{V} \in \tau_{2} \exists \mathrm{T}^{-1}(\mathrm{U}), \mathrm{T}^{-1}(\mathrm{~V}) \in \tau_{1}$

$\Rightarrow$ For every measurable sets $\mathrm{A}, \mathrm{B} \in \Sigma_{2} \exists \mathrm{T}^{-1}(\mathrm{~A}), \mathrm{T}^{-1}(\mathrm{~B}) \in \Sigma_{1}$ such that 
$\mu_{1}\left(\left(\mathrm{~T}^{-1}\right)^{-1}(\mathrm{~A})\right)=\mu_{2}(\mathrm{~A})$ and $\mu_{1}\left(\left(\mathrm{~T}^{-1}\right)^{-1}(\mathrm{~B})\right)=\mu_{2}(\mathrm{~B}) \cdots \cdots \cdots($ iii $)$

Therefore we conclude that Hausdorff property is preserved under the transformation $\mathrm{T}$.

Step-III:

Consider the mapping

$\mathrm{T}^{-1}:\left(\mathrm{R}^{\mathrm{m}}, \tau_{2}, \Sigma_{2}, \mu_{2}\right) \rightarrow\left(\mathrm{R}^{\mathrm{n}}, \tau_{1}, \Sigma_{1}, \mu_{1}\right)$

From Step- I and II, similarly it follows that $\mathrm{T}^{-1}$ is measurable and measure invariant.

$\Rightarrow$ For every measurable subsets $\mathrm{C}, \mathrm{D} \in \Sigma_{1}$ with $\mathrm{p} \in \mathrm{C}, \mathrm{p} \notin \mathrm{D}$ and $\mathrm{q} \in \mathrm{D}, \mathrm{q} \notin \mathrm{C}$ and

$\mu_{1}(\mathrm{C} \cap \mathrm{D})=\mu_{1}(\varnothing)=0 \cdots \cdots \cdots($ iv $)$

Also for every measurable subsets $\mathrm{C}, \mathrm{D} \in \Sigma_{1} \exists\left(\mathrm{T}^{-1}\right)^{-1}(\mathrm{C}),\left(\mathrm{T}^{-1}\right)^{-1}(\mathrm{D}) \in \Sigma_{2}$ such that $\left(\left(\mathrm{T}^{-1}\right)^{-1}(\mathrm{p}) \in\right.$ $\left(\left(\mathrm{T}^{-1}\right)^{-1}(\mathrm{C}),\left(\left(\mathrm{T}^{-1}\right)^{-1}(\mathrm{p}) \notin\left(\left(\mathrm{T}^{-1}\right)^{-1}(\mathrm{D})\right.\right.\right.$ and $\left(\left(\mathrm{T}^{-1}\right)^{-1}(\mathrm{q}) \in\left(\left(\mathrm{T}^{-1}\right)^{-1}(\mathrm{D}),\left(\left(\mathrm{T}^{-1}\right)^{-1}(\mathrm{q}) \notin\left(\left(\mathrm{T}^{-1}\right)^{-1}(\mathrm{C}) \quad\right.\right.\right.\right.$ and $\mu_{2}\left(\left(\mathrm{~T}^{-1}\right)^{-1}(\mathrm{C}) \cap\left(\mathrm{T}^{-1}\right)^{-1}(\mathrm{D})\right)=\mu_{2}(\varnothing)=0 \cdots \cdots \cdots(\mathrm{v})$

$\Rightarrow \mathrm{T}^{-1}$ is measurable

Also for every measurable subsets $\mathrm{C}, \mathrm{D} \in \Sigma_{1} \exists\left(\mathrm{T}^{-1}\right)^{-1}(\mathrm{C}),\left(\mathrm{T}^{-1}\right)^{-1}(\mathrm{D}) \in \Sigma_{2}$ such that $\mu_{2}\left(\left(\mathrm{~T}^{-1}\right)^{-1}(\mathrm{C})\right)=$ $\mu_{1}(\mathrm{C})$ and $\mu_{2}\left(\left(\mathrm{~T}^{-1}\right)^{-1}(\mathrm{D})\right)=\mu_{1}(\mathrm{D}) \cdots \cdots \cdots(\mathrm{vi})$

Therefore from equations (iv),(v) and (vi)

It is observed that Hausdorff property is preserved under the transformation $\mathrm{T}^{-1}$.

Hence Hausdorff property is invariant under measure transformations $\mathrm{T}$ and $\mathrm{T}^{-1}$

Theorem 2. On a measure space $\left(\mathrm{R}^{\mathrm{n}}, \tau_{1}, \Sigma_{1}, \mu_{1}\right)$ if regularity is a topological invariant under homeomorphism then it is invariant under measure transformation.

Proof: Let $\left(\mathrm{R}^{\mathrm{n}}, \tau_{1}\right)$ be a regular space such that $\exists$ a homeomorphism $\mathrm{T}:\left(\mathrm{R}^{\mathrm{n}}, \tau_{1}, \Sigma_{1}, \mu_{1}\right) \rightarrow\left(\mathrm{R}^{\mathrm{m}}, \tau_{2}, \Sigma_{2}, \mu_{2}\right)$ with reference to topological structure then $\left(\mathrm{R}^{\mathrm{m}}, \tau_{2}\right)$ is also a regular space.

By proposition 1, For every topological homeomorphism between $\left(\mathrm{R}^{\mathrm{n}}, \tau_{1}, \Sigma_{1}, \mu_{1}\right)$ and $\left(\mathrm{R}^{\mathrm{m}}, \tau_{2}, \Sigma_{2}, \mu_{2}\right) \exists$ a measure invariant transformations

$$
\begin{array}{r}
\mathrm{T}:\left(\mathrm{R}^{\mathrm{n}}, \tau_{1}, \Sigma_{1}, \mu_{1}\right) \rightarrow\left(\mathrm{R}^{\mathrm{m}}, \tau_{2}, \Sigma_{2}, \mu_{2}\right) \\
\text { and } \quad \mathrm{T}^{-1}:\left(\mathrm{R}^{\mathrm{m}}, \tau_{2}, \Sigma_{2}, \mu_{2}\right) \rightarrow\left(\mathrm{R}^{\mathrm{n}}, \tau_{1}, \Sigma_{1}, \mu_{1}\right)
\end{array}
$$

such that $\mathrm{T}$ and $\mathrm{T}^{-1}$ are measurable and measure invariant.

Step- I:

Let us show that $\exists$ a map $T:\left(\mathrm{R}^{\mathrm{n}}, \tau_{1}, \Sigma_{1}, \mu_{1}\right) \rightarrow\left(\mathrm{R}^{\mathrm{m}}, \tau_{2}, \Sigma_{2}, \mu_{2}\right)$ which preserves the regularity property under measure transformation. Since $\mathrm{R}^{\mathrm{m}}$ is a regular space with reference to topological structure $\tau_{2}$, then for every point $\mathrm{q} \in \mathrm{R}^{\mathrm{m}}$ and a closed set $F$ in $\mathrm{R}^{\mathrm{m}}$ not containing $\mathrm{q} \exists$ open sets $U$ and $V$ in $\tau_{2}$ such that $\mathrm{q} \in \mathrm{U}, \mathrm{F} \subset \mathrm{V}$ and $\mathrm{U} \cap \mathrm{V}=\varnothing$

Since $\mathrm{T}$ is homeomorphism

$\Rightarrow \mathrm{T}$ is continuous

$\Rightarrow$ for every point $\mathrm{q}$ and closed set $\mathrm{F}$ in $\mathrm{R}^{\mathrm{m}} \exists \mathrm{T}^{-1}(\mathrm{q})$ and closed set $\mathrm{T}^{-1}(\mathrm{~F})$ in $\mathrm{R}^{\mathrm{n}}$. Also $\mathrm{R}^{\mathrm{n}}$ is regular space with reference to topological structure $\tau_{1}$, then for every point $\mathrm{T}^{-1}(\mathrm{q})$ and closed set $\mathrm{T}^{-1}(\mathrm{~F})$ in $\mathrm{R}^{\mathrm{n}} \exists$ open sets $\mathrm{T}^{-1}(\mathrm{U})$ and $\mathrm{T}^{-1}(\mathrm{v})$ in $\tau_{1}$ such that $\mathrm{T}^{-1}(\mathrm{q}) \in \mathrm{T}^{-1}(\mathrm{U})$ and $\mathrm{T}^{-1}(\mathrm{~F}) \subset \mathrm{T}^{-1}(\mathrm{~V})$ and $\mathrm{T}^{-1}(\mathrm{U}) \cap \mathrm{T}^{-1}(\mathrm{~V})=\mathrm{T}^{-1}(\mathrm{U} \cap$ $\mathrm{V})=\mathrm{T}^{-1}(\varnothing)=\varnothing$. [ because $\mathrm{T}$ is onto].

since for every point $q$ and closed set $F$ in $R^{m} \exists$ open sets $U, V \in \tau_{2}$ which generates corresponding Borel sets $\mathrm{A}, \mathrm{B} \in \Sigma_{2}$ such that $\mathrm{A}, \mathrm{B}$ are measurable in $\left(\mathrm{R}^{\mathrm{m}}, \tau_{2}, \Sigma_{2}, \mu_{2}\right)$.

Therefore for every $\mathrm{U}, \mathrm{V} \in \tau_{2} \exists$ measurable sets $\mathrm{A}, \mathrm{B} \in \Sigma_{2}$ such that $\mathrm{q} \in \mathrm{A}, \mathrm{F} \subset \mathrm{B}$ and

$\mu_{2}(\mathrm{~A} \cap \mathrm{B})=\mu_{2}(\emptyset)=0 \cdots \cdots$ (i)

and every open sets $\mathrm{T}^{-1}(\mathrm{U}), \mathrm{T}^{-1}(\mathrm{~V}) \in \tau_{1}$ generates Borel sets $\mathrm{T}^{-1}(\mathrm{~A}), \mathrm{T}^{-1}(\mathrm{~B}) \in \Sigma_{1}$ such that $\mathrm{T}^{-1}(\mathrm{q}) \in$ $\mathrm{T}^{-1}(\mathrm{~A}), \mathrm{T}^{-1}(\mathrm{~F}) \subset \mathrm{T}^{-1}(\mathrm{~B})$ and $\mu_{1}\left(\mathrm{~T}^{-1}(\mathrm{~A}) \cap \mathrm{T}^{-1}(\mathrm{~B})\right)=\mu_{1}(\varnothing)=0 \cdots \cdots$ (ii)

$\Rightarrow \mathrm{T}$ is measurable.

Step II:

Also to show that $\mathrm{T}$ preserves the regularity property under measure transformation .

Because $\mathrm{T}$ and $\mathrm{T}^{-1}$ are continuous

$\Longrightarrow$ For every $U, V \in \tau_{2} \exists T^{-1}(U), T^{-1}(V) \in \tau_{1}$

$\Rightarrow$ For every measurable sets $\mathrm{A}, \mathrm{B} \in \Sigma_{2} \exists \mathrm{T}^{-1}(\mathrm{~A}), \mathrm{T}^{-1}(\mathrm{~B}) \in \Sigma_{1}$ such that

$$
\mu_{1}\left(\mathrm{~T}^{-1}(\mathrm{~A})\right)=\mu_{2}(\mathrm{~A}) \text { and } \mu_{1}\left(\mathrm{~T}^{-1}(\mathrm{~B})\right)=\mu_{2}(\mathrm{~B}) \cdots \cdots \text { (iii) }
$$

Therefore we conclude that regularity is invariant under measure transformation $\mathrm{T}$.

Step- III:

Now we show that $\mathrm{T}^{-1}$ is also measurable and measure invariant.

$$
\mathrm{T}^{-1}:\left(\mathrm{R}^{\mathrm{m}}, \tau_{2}, \Sigma_{2}, \mu_{2}\right) \rightarrow\left(\mathrm{R}^{\mathrm{n}}, \tau_{1}, \Sigma_{1}, \mu_{1}\right)
$$

From step I and II similar observations can be seen in the transformation $\mathrm{T}^{-1}$ i.e., $\mathrm{T}^{-1}$ is measurable and measure invariant. 
$\Longrightarrow$ for every measurable sets $C, D \in \Sigma_{1}$ with $\mathrm{q} \in \mathrm{C}, \mathrm{F} \subset \mathrm{D}$ and $\mu_{1}(\mathrm{C} \cap \mathrm{D})=\mu_{1}(\emptyset)=0 \cdots \cdots$ (iv )

Also for every measurable sets $\mathrm{C}, \mathrm{D} \in \Sigma_{1} \exists\left(\mathrm{T}^{-1}\right)^{-1}(\mathrm{C}),\left(\mathrm{T}^{-1}\right)^{-1}(\mathrm{D}) \in \Sigma_{2}$ such that $\left(\mathrm{T}^{-1}\right)^{-1}(\mathrm{q}) \in$ $\left(\mathrm{T}^{-1}\right)^{-1}(\mathrm{C}),\left(\mathrm{T}^{-1}\right)^{-1}(\mathrm{~F}) \subset\left(\mathrm{T}^{-1}\right)^{-1}(\mathrm{D})$ and $\mu_{2}\left(\left(\mathrm{~T}^{-1}\right)^{-1}(\mathrm{C}) \cap\left(\mathrm{T}^{-1}\right)^{-1}(\mathrm{D})\right)=\mu_{2}(\varnothing)=0 \cdots \cdots \cdots(\mathrm{v})$

$\Rightarrow \mathrm{T}^{-1}$ is measurable

Also, $\mathrm{T}^{-1}$ preserves the regularity property under measure transformation.

$\Rightarrow$ for every measurable sets $C, D \in \Sigma_{1} \exists\left(\mathrm{T}^{-1}\right)^{-1}(\mathrm{C}),\left(\mathrm{T}^{-1}\right)^{-1}(\mathrm{D}) \in \Sigma_{2}$ such that $\mu_{2}\left(\left(\mathrm{~T}^{-1}\right)^{-1}(\mathrm{C})\right)=\mu_{1}(\mathrm{C})$ and $\mu_{2}\left(\left(\mathrm{~T}^{-1}\right)^{-1}(\mathrm{D})\right)=\mu_{1}(\mathrm{D}) \cdots \cdots \cdots(\mathrm{vi})$

$\Longrightarrow$ The regularity property is preserved under measure transformation $\mathrm{T}^{-1}$.

Therefore from steps I, II and III it is confirmed that regularity is invariant under measure transformations $\mathrm{T}$ and $\mathrm{T}^{-1}$

Theorem 3. Atomic Hausdorff property is invariant under measure transformation.

Proof : Let $\left(\mathrm{R}^{\mathrm{m}}, \tau_{2}, \Sigma_{2}, \mu_{\mathrm{A}_{2}}\right)$ be atomic Hausdorff space.

By Theorem 1, If Hausdorff property is topological invariant under homeomorphism then it is invariant under measure transformations.

Now let us show that $\exists$ a mapping

$$
\begin{array}{r}
\mathrm{T}:\left(\mathrm{R}^{\mathrm{n}}, \tau_{1}, \Sigma_{1}, \mu_{1}\right) \rightarrow\left(\mathrm{R}^{\mathrm{m}}, \tau_{2}, \Sigma_{2}, \mu_{2}\right) \\
\text { and } \mathrm{T}^{-1}:\left(\mathrm{R}^{\mathrm{m}}, \tau_{2}, \Sigma_{2}, \mu_{2}\right) \rightarrow\left(\mathrm{R}^{\mathrm{n}}, \tau_{1}, \Sigma_{1}, \mu_{1}\right)
\end{array}
$$

$$
\begin{array}{r}
\mathrm{T}_{1}:\left(\mathrm{R}^{\mathrm{n}}, \tau_{1}, \Sigma_{1}, \mu_{\mathrm{A}_{1}}\right) \rightarrow\left(\mathrm{R}^{\mathrm{m}}, \tau_{2}, \Sigma_{2}, \mu_{\mathrm{A}_{2}}\right) \\
\text { and } \mathrm{T}_{1}^{-1}:\left(\mathrm{R}^{\mathrm{m}}, \tau_{2}, \Sigma_{2}, \mu_{\mathrm{A}_{2}}\right) \rightarrow\left(\mathrm{R}^{\mathrm{n}}, \tau_{1}, \Sigma_{1}, \mu_{\mathrm{A}_{1}}\right)
\end{array}
$$

with atomic measures $\mu_{\mathrm{A}_{1}}$ and, $\mu_{\mathrm{A}_{2}}$ on $\mathrm{R}^{\mathrm{n}}$ and $\mathrm{R}^{\mathrm{m}}$ respectively which preserves the atomic Hausdorff property under measure transformation.

Step-I:

First, let us show that $\exists$ a mapping $\mathrm{T}_{1}:\left(\mathrm{R}^{\mathrm{n}}, \tau_{1}, \Sigma_{1}, \mu_{\mathrm{A}_{1}}\right) \rightarrow\left(\mathrm{R}^{\mathrm{m}}, \tau_{2}, \Sigma_{2}, \mu_{\mathrm{A}_{2}}\right)$ which preserves the atomic Hausdorff property under measure transformation.

Since $\left(\mathrm{R}^{\mathrm{m}}, \tau_{2}, \Sigma_{2}, \mu_{\mathrm{A}_{2}}\right)$ is atomic Hausdorff space, for every point $\mathrm{p}, \mathrm{q} \in \mathrm{R}^{\mathrm{m}} \exists$ atomic Borel open sets $\mathrm{A}, \mathrm{B} \in \Sigma_{2}$ such that $\mathrm{p} \in \mathrm{A}, \mathrm{p} \notin \mathrm{B}$ and $\mathrm{q} \in \mathrm{B}, \mathrm{q} \notin \mathrm{A}$ such that $\mathrm{A} \cap \mathrm{B}=\varnothing$ and satisfying the atomic measure conditions:

i)for $\mathrm{p} \in \mathrm{A} \exists \mathrm{C} \in \Sigma_{2}, \mathrm{C} \subset \mathrm{A}$ and has either $\mu_{\mathrm{A}_{2}}(\mathrm{C})=0$ or $\mu_{\mathrm{A}_{2}}(\mathrm{C})=\mu_{\mathrm{A}_{2}}(\mathrm{~A})$

ii) for $\mathrm{q} \in \mathrm{B} \exists \mathrm{D} \in \Sigma_{2}, \mathrm{D} \subset \mathrm{B}$ and has either $\mu_{\mathrm{A}_{2}}(\mathrm{D})=0$ or $\mu_{\mathrm{A}_{2}}(\mathrm{D})=\mu_{\mathrm{A}_{2}}(\mathrm{~B})$ and $\mu_{\mathrm{A}_{2}}(\mathrm{~A} \cap \mathrm{B})=\mu_{\mathrm{A}_{2}}(\varnothing)=0 \cdots \cdots$ (i) Again by using Theorem 1, we write for every atomic Borel open sets $A, B \in \Sigma_{2} \exists \mathrm{T}_{1}^{-1}(\mathrm{~A}), \mathrm{T}_{1}^{-1}(\mathrm{~B}) \in \Sigma_{1}$ such that $\mathrm{T}_{1}^{-1}(\mathrm{p}) \in \mathrm{T}_{1}^{-1}(\mathrm{~A}), \mathrm{T}_{1}^{-1}(\mathrm{q}) \in \mathrm{T}_{1}^{-1}(\mathrm{~B})$ and satisfying the atomic measure conditions:

i) for $\mathrm{T}_{1}^{-1}(\mathrm{p}) \in \mathrm{T}_{1}^{-1}(\mathrm{~A}) \exists \mathrm{T}_{1}^{-1}(\mathrm{C}) \in \Sigma_{1}, \mathrm{~T}_{1}^{-1}(\mathrm{C}) \subset \mathrm{T}_{1}^{-1}$ (A) and has either $\mu_{\mathrm{A}_{1}}\left(\mathrm{~T}_{1}^{-1}(\mathrm{C})\right)=0$ or $\mu_{\mathrm{A}_{1}}\left(\mathrm{~T}_{1}^{-1}\right.$ (C) $)=\mu_{\mathrm{A}_{1}}\left(\mathrm{~T}_{1}^{-1}(\mathrm{~A})\right)$

ii) for $\mathrm{T}_{1}^{-1}$ (q) $\in \mathrm{T}_{1}^{-1}$ (B) $\exists \mathrm{T}_{1}^{-1}$ (D) $\in \Sigma_{1}, \mathrm{~T}_{1}^{-1}$ (D) $\subset \mathrm{T}_{1}^{-1}$ (B) and has either $\mu_{\mathrm{A}_{1}}\left(\mathrm{~T}_{1}^{-1}\right.$ (D)) $=0$ or $\mu_{\mathrm{A}_{1}}\left(\mathrm{~T}_{1}^{-1}\right.$ (D) $)=\mu_{\mathrm{A}_{1}}\left(\mathrm{~T}_{1}^{-1}(\mathrm{~B})\right)$ and $\mu_{\mathrm{A}_{1}}\left(\mathrm{~T}_{1}^{-1}(\mathrm{~A}) \cap \mathrm{T}_{1}^{-1}(\mathrm{~B})\right)=\mu_{\mathrm{A}_{1}}(\varnothing)=0 \cdots \cdots$ (ii)

$\Rightarrow \mathrm{T}_{1}$ is measurable.

Step-II:

Also to show that $\mathrm{T}_{1}$ preserves the atomic Hausdorff property under measure transformation.

since for every atomic Borel open sets $\mathrm{A}, \mathrm{B} \in \Sigma_{2} \exists$ atomic Borel open sets $\mathrm{T}_{1}^{-1}(\mathrm{~A}), \mathrm{T}_{1}^{-1}(\mathrm{~B}) \in \Sigma_{1}$ [since $\mathrm{T}_{1}$ is measurable]

such that $\mu_{\mathrm{A}_{1}}\left(\mathrm{~T}_{1}^{-1}(\mathrm{~A})\right)=\mu_{\mathrm{A}_{2}}(\mathrm{~A})$ and $\mu_{\mathrm{A}_{1}}\left(\mathrm{~T}_{1}^{-1}(\mathrm{~B})\right)=\mu_{\mathrm{A}_{2}}(\mathrm{~B}) \cdots \cdots$ (iii)

Therefore from (i), (ii) and (iii)

We confirm that atomic Hausdorff property is preserved under the transformation $\mathrm{T}_{1}$.

Step-III:

Consider the mapping $\mathrm{T}_{1}^{-1}:\left(\mathrm{R}^{\mathrm{m}}, \tau_{2}, \Sigma_{2}, \mu_{\mathrm{A}_{2}}\right) \rightarrow\left(\mathrm{R}^{\mathrm{n}}, \tau_{1}, \Sigma_{1}, \mu_{\mathrm{A}_{1}}\right)$

By interchanging the roles of $\mathrm{R}^{\mathrm{n}}$ and $\mathrm{R}^{\mathrm{m}}$ and corresponding measure spaces we conclude that $\exists$ a mapping $\mathrm{T}_{1}^{-1}$ which is measurable and measure invariant.

Therefore from Step-I, II and III, we come to the conclusion that atomic regularity is invariant under measure invariant transformations $\mathrm{T}_{1}$ and $\mathrm{T}_{1}^{-1}$

Theorem 4. Atomic regularity is invariant under measure transformation.

Proof : Let $\left(\mathrm{R}^{\mathrm{m}}, \tau_{2}, \Sigma_{2}, \mu_{\mathrm{A}_{2}}\right)$ be atomic regular space.

By Theorem 2, If regularity is a topological invariant under homeomorphism then it is invariant under measure transformations.

Now let us show that $\exists$ a mapping

$$
\begin{array}{r}
\mathrm{T}:\left(\mathrm{R}^{\mathrm{n}}, \tau_{1}, \Sigma_{1}, \mu_{1}\right) \rightarrow\left(\mathrm{R}^{\mathrm{m}}, \tau_{2}, \Sigma_{2}, \mu_{2}\right) \\
\text { and } \mathrm{T}^{-1}:\left(\mathrm{R}^{\mathrm{m}}, \tau_{2}, \Sigma_{2}, \mu_{2}\right) \rightarrow\left(\mathrm{R}^{\mathrm{n}}, \tau_{1}, \Sigma_{1}, \mu_{1}\right)
\end{array}
$$




$$
\begin{array}{r}
\mathrm{T}_{1}:\left(\mathrm{R}^{\mathrm{n}}, \tau_{1}, \Sigma_{1}, \mu_{\mathrm{A}_{1}}\right) \rightarrow\left(\mathrm{R}^{\mathrm{m}}, \tau_{2}, \Sigma_{2}, \mu_{\mathrm{A}_{2}}\right) \\
\text { and } \mathrm{T}_{1}^{-1}:\left(\mathrm{R}^{\mathrm{m}}, \tau_{2}, \Sigma_{2}, \mu_{\mathrm{A}_{2}}\right) \rightarrow\left(\mathrm{R}^{\mathrm{n}}, \tau_{1}, \Sigma_{1}, \mu_{\mathrm{A}_{1}}\right)
\end{array}
$$

with atomic measures $\mu_{\mathrm{A}_{1}}$ and,$\mu_{\mathrm{A}_{2}}$ on $\mathrm{R}^{\mathrm{n}}$ and $\mathrm{R}^{\mathrm{m}}$ respectively which preserves the atomic regularity under measure transformation.

Step-I:

First, let us show that $\exists$ a mapping $\mathrm{T}_{1}:\left(\mathrm{R}^{\mathrm{n}}, \tau_{1}, \Sigma_{1}, \mu_{\mathrm{A}_{1}}\right) \rightarrow\left(\mathrm{R}^{\mathrm{m}}, \tau_{2}, \Sigma_{2}, \mu_{\mathrm{A}_{2}}\right)$ which preserves the atomic regularity property under measure transformation.

Since $\left(\mathrm{R}^{\mathrm{m}}, \tau_{2}, \Sigma_{2}, \mu_{\mathrm{A}_{2}}\right)$ is atomic regular space, for every point $\mathrm{q} \in \mathrm{R}^{\mathrm{m}}$ and atomic Borel closed set $\mathrm{F}$ in $\mathrm{R}^{\mathrm{m}}$ not containing $\mathrm{q} \exists$ atomic Borel open sets $\mathrm{A}, \mathrm{B} \in \Sigma_{2}$ such that $\mathrm{q} \in \mathrm{A}, \mathrm{F} \subset \mathrm{B}$ and $\mathrm{A} \cap \mathrm{B}=\emptyset$. Satisfying the atomic measure conditions:

i)for $\mathrm{q} \in \mathrm{A} \exists \mathrm{C} \in \Sigma_{2}, \mathrm{C} \subset \mathrm{A}$ and has either $\mu_{\mathrm{A}_{2}}(\mathrm{C})=0$ or $\mu_{\mathrm{A}_{2}}(\mathrm{C})=\mu_{\mathrm{A}_{2}}(\mathrm{~A})$

ii) for $\mathrm{F} \subset \mathrm{B} \exists \mathrm{D} \in \Sigma_{2}, \mathrm{D} \subset \mathrm{B}$ and has either $\mu_{\mathrm{A}_{2}}(\mathrm{D})=0$ or $\mu_{\mathrm{A}_{2}}(\mathrm{D})=\mu_{\mathrm{A}_{2}}(\mathrm{~B})$ and $\mu_{\mathrm{A}_{2}}(\mathrm{~A} \cap \mathrm{B})=\mu_{\mathrm{A}_{2}}(\varnothing)=0 \cdots \cdots(\mathrm{i})$

Again by using Theorem 2, we write for every atomic Borel open sets $A, B \in \Sigma_{2} \exists T_{1}^{-1}(A), T_{1}^{-1}(B) \in \Sigma_{1}$ such that $\mathrm{T}_{1}^{-1}(\mathrm{q}) \in \mathrm{T}_{1}^{-1}(\mathrm{~A}), \mathrm{T}_{1}^{-1}(\mathrm{~F}) \subset \mathrm{T}_{1}^{-1}(\mathrm{~B})$ and satisfying the atomic measure conditions:

i) for $\mathrm{T}_{1}^{-1}(\mathrm{q}) \in \mathrm{T}_{1}^{-1}(\mathrm{~A}) \exists \mathrm{T}_{1}^{-1}(\mathrm{C}) \in \Sigma_{1}, \mathrm{~T}_{1}^{-1}(\mathrm{C}) \subset \mathrm{T}_{1}^{-1}(\mathrm{~A})$ and has either $\mu_{\mathrm{A}_{1}}\left(\mathrm{~T}_{1}^{-1}(\mathrm{C})\right)=0$ or $\mu_{\mathrm{A}_{1}}\left(\mathrm{~T}_{1}^{-1}\right.$ (C) $)=\mu_{\mathrm{A}_{1}}\left(\mathrm{~T}_{1}^{-1}(\mathrm{~A})\right)$

ii) for $\mathrm{T}_{1}^{-1}(\mathrm{~F}) \subset \mathrm{T}_{1}^{-1}$ (B) $\exists \mathrm{T}_{1}^{-1}$ (D) $\in \Sigma_{1}, \mathrm{~T}_{1}^{-1}$ (D) $\subset \mathrm{T}_{1}^{-1}$ (B) and has either $\mu_{\mathrm{A}_{1}}\left(\mathrm{~T}_{1}^{-1}\right.$ (D)) $=0$ or $\mu_{\mathrm{A}_{1}}\left(\mathrm{~T}_{1}^{-1}\right.$ (D) $)=\mu_{\mathrm{A}_{1}}\left(\mathrm{~T}_{1}^{-1}(\mathrm{~B})\right)$ and $\mu_{\mathrm{A}_{1}}\left(\mathrm{~T}_{1}^{-1}(\mathrm{~A}) \cap \mathrm{T}_{1}^{-1}(\mathrm{~B})\right)=\mu_{\mathrm{A}_{1}}(\varnothing)=0 \cdots \cdots$ (ii)

$\Rightarrow \mathrm{T}_{1}$ is measurable.

Step-II:

Also to show that $\mathrm{T}_{1}$ preserves the atomic regularity under measure transformation.

since for every atomic Borel open sets $\mathrm{A}, \mathrm{B} \in \Sigma_{2} \exists$ atomic Borel open sets $\mathrm{T}_{1}^{-1}(\mathrm{~A}), \mathrm{T}_{1}^{-1}(\mathrm{~B}) \in \Sigma_{1}$ [since $\mathrm{T}_{1}$ is measurable]

such that $\mu_{\mathrm{A}_{1}}\left(\mathrm{~T}_{1}^{-1}(\mathrm{~A})\right)=\mu_{\mathrm{A}_{2}}(\mathrm{~A})$ and $\mu_{\mathrm{A}_{1}}\left(\mathrm{~T}_{1}^{-1}(\mathrm{~B})\right)=\mu_{\mathrm{A}_{2}}(\mathrm{~B}) \cdots \cdots$ (iii)

Therefore from (i),(ii) and (iii)

We confirm that atomic regularity is preserved under the transformation $\mathrm{T}_{1}$.

Step-III:

Consider the mapping $\mathrm{T}_{1}^{-1}:\left(\mathrm{R}^{\mathrm{m}}, \tau_{2}, \Sigma_{2}, \mu_{\mathrm{A}_{2}}\right) \rightarrow\left(\mathrm{R}^{\mathrm{n}}, \tau_{1}, \Sigma_{1}, \mu_{\mathrm{A}_{1}}\right)$

By interchanging the roles of $\mathrm{R}^{\mathrm{n}}$ and $\mathrm{R}^{\mathrm{m}}$ and corresponding measure spaces we conclude that $\exists$ a mapping $\mathrm{T}_{1}^{-1}$ which is measurable and measure invariant.

Therefore from Step-I, II and III we come to the conclusion that atomic regularity is invariant under measure invariant transformations $\mathrm{T}_{1}$ and $\mathrm{T}_{1}^{-1}$

\section{Conclusion}

In our study, it is observed that the measure space carrying topological and $\sigma$-algebraic structures, inherits two invariants. The topological structures on $\left(\mathrm{R}^{\mathrm{n}}, \tau, \Sigma, \mu\right)$ that are invariant under homeomorphism are also invariant under measure invariant transformation. This study enriches the analysis on $\left(\mathrm{R}^{\mathrm{n}}, \tau, \Sigma, \mu\right)$ and such measure space $\left(\mathrm{R}^{\mathrm{n}}, \tau, \Sigma, \mu\right)$ becomes structurally potential enough to generate a measure manifold. The study of atomic separation axioms on the measure manifold has its applications in the field of cosmology, where the universe could be modeled as atomic measure manifold. The atomic separation axioms explicitly explain the expansion of the universe as the intrinsic property of atomic measure manifold. The advantage of introducing the concept of measure manifold is in the field of Engineering Science, Brain Science and Neural Network.

\section{References:}

[1]. S. C. P. Halakatti and H. G. Haloli, "Introducing the Concept of Measure Manifold $\left(\mathrm{M}, \Sigma_{1}, \tau_{1}, \mu_{1}\right)$ ", IOSR Journal of Mathematics(IOSR-JM), Volume10, Issue 3 Ver. II, 01-11(2014)

[2]. John K Hunter, "Measure Theory Lecture notes", University of California at davis(2011)

[3]. C. W. Patty, "Foundations of Topology", Jones and Bartlett Publications Inc., First Indian edition(2010)

[4]. M. M. Rao, "Measure Theory and Integration", Second Edition, Marcel Dekkar, INC., New York-Basel(2004)

[5]. R. K. Singh and T. Veluchamy, "Atomic Measure Space and Essential Normal Composition Operators", Bull Austral Math, Soc., Vol. 27(1983)

[ 6 ] . O. Ya. Viro, O. A. Ivanov, N. Yu. Netsvetaev, V. M. Kharlamov, "Elementary Topology problem Textbook", AMS, HyderabadIndia(2012) 